\title{
Design criterion for fatigue strengthening of riveted beams in a 120-year-old railway metallic bridge using pre-stressed CFRP plates ${ }^{1}$
}

\begin{abstract}
This study presents a design criterion developed for fatigue strengthening of a 120-year-old metallic railway bridge in Switzerland and presents a pre-stressed un-bonded reinforcement (PUR) system developed to apply the strengthening. The PUR system uses carbon fiber reinforced polymer (CFRP) plates; however, unlike conventional pre-stressed CFRP reinforcement methods, preparation of the existing metallic bridge surface is not required. This decreases the time required for on-site strengthening procedures. The principle of the constant life diagram (CLD) and two fatigue failure criteria (Johnson and Goodman) are described. Analytical formulations are developed based on the CLD method to determine the minimum CFRP pre-stress level required to prevent fatigue crack initiation. The PUR system uses an applied pre-stress force to reduce the mean stress level (and stress ratio) to shift an existing fatigue-susceptible metallic detail from the 'at risk' finite life regime to the 'safe' infinite life regime. The applied CLD method is particularly valuable when the stress history of the detail is not known and it is difficult to assess the remaining fatigue life. Moreover, it is shown that the currently adopted approach in many structural codes which emphasizes stress range as the dominant parameter influencing fatigue life are non-conservative for tension-tension stress patterns (i.e., stress ratios of $0<\mathrm{R}<1$ ). Analyses show that the modified Johnson formula accurately reflects the combined effect of stress range, mean stress level, and material properties, and offers a relatively easy design procedure. Details of a retrofit field application on members of a riveted wrought iron railway bridge are given. A wireless sensor network (WSN) system is used for long-term monitoring of the on-site CFRP stress levels and temperature of the retrofitted details. WSN measurements indicate that increases in ambient temperature result in increased CFRP pre-stress levels.
\end{abstract}

Keywords: Carbon fiber; Laminates; Fatigue; Finite element analysis (FEA); retrofit.

\footnotetext{
${ }^{1}$ Ghafoori, E., Motavalli, M., Nussbaumer, A., Herwig, A., Prinz, G.S., and Fontana, M., Composites Part B, 2015. 68: p. 1-13.
} 


\section{Abbreviations}

CLD constant life diagram

CFRP carbon fiber reinforced polymer

HDPE high-density polyethylene

$\mathrm{k}_{\mathrm{c}} \quad$ load modification factor

WSN wireless sensor network

SIF stress intensity factor

SCF stress-concentration factor

$\mathrm{FE}$ finite element

$\mathrm{k}_{\mathrm{d}} \quad$ temperature modification factor

$\mathrm{k}_{\mathrm{e}} \quad$ reliability modification factor

q notch sensitivity parameter

$\sqrt{a} \quad$ Neuber constant

$r \quad$ radius of notch

$\sigma_{\min }, \sigma_{\max }$ minimum and maximum stresses

$\sigma^{0} \quad$ nominal stress

$\sigma_{\mathrm{a}}=\left|\frac{\sigma_{\max }-\sigma_{\min }}{2}\right| \quad$ stress amplitude

$\sigma^{\infty} \quad$ stress far from hole

$\sigma_{\mathrm{m}}=\frac{\sigma_{\mathrm{max}}+\sigma_{\mathrm{min}}}{2} \quad$ midrange (mean) stress

$\sigma^{\mathrm{h}} \quad$ maximum stress at hole location

d diameter of hole

$\mathrm{R}=\frac{\sigma_{\min }}{\sigma_{\max }} \quad$ stress ratio

w width of plate

$\mathrm{S}_{\mathrm{y}} \quad$ yield strength

$\mathrm{S}_{\mathrm{ut}} \quad$ ultimate tensile strength

$\sigma_{\mathrm{a}} \quad$ alternating stress

$\sigma_{\mathrm{m}} \quad$ midrange stress

$\mathrm{S}_{\mathrm{e}}^{\prime} \quad$ endurance limit of rotary-beam test specimen

n safety factor

$\mathrm{h}, \mathrm{A}_{\mathrm{m}}, \mathrm{I}_{\mathrm{m}}$ height, area and inertia of metallic cross-section

$\mathrm{A}_{\mathrm{p}} \quad$ net cross-section area of CFRP plates

e eccentricity between CFRP plate and beam neutral plane

F vertical load applied by each hydraulic

$\mathrm{S}_{\mathrm{e}}$ endurance limit in geometry and condition of use actuator

$F_{\text {pre }} \quad$ net force in CFRP plates

$\mathrm{N}$ total number of cycles to failure

$\sigma_{\text {pre }} \quad$ CFRP pre-stress

$\mathrm{n}_{\mathrm{bs}}, \mathrm{n}_{\mathrm{as}}$ applied number of cycles 'before' and 'after' strengthening

D overall accumulated damage

$\mathrm{e}_{\mathrm{c}} \quad$ height of clamp

$e_{p}^{i} \quad$ initial deflection of CFRP plates due to

$\mathrm{A}_{0.95 \sigma}$ area of stressed at $95 \%$ self-weight

$\mathrm{T}_{\mathrm{c}} \quad$ temperature in degree Celsius

$e_{p} \quad$ final eccentricity of CFRP plates

$\mathrm{L}_{\mathrm{i}} \quad$ initial length of CFRP plates

$\mathrm{k}_{\mathrm{t}} \quad$ stress-concentration factor (SCF)

$\mathrm{L}_{\mathrm{f}} \quad$ final length of CFRP plates

$\mathrm{k}_{\mathrm{f}} \quad$ fatigue $\mathrm{SCF}$

$\mathrm{k}_{\mathrm{a}} \quad$ surface condition modification factor

$\sigma_{m^{*}}, \sigma_{a^{*}} \quad$ stresses in metal before

$\mathrm{k}_{\mathrm{b}} \quad$ size modification factor

strengthening

$\sigma_{m^{* *}}$ mean stress in metal after strengthening

\subsubsection{Introduction}

Aging of metallic bridge structures is a world-wide problem requiring attention. In Europe, nearly $70 \%$ of all metallic bridges are more than 50 years old, with $30 \%$ of all bridges having been in service for over 100 years [1]. In the United States, the US Department of Transportation indicates that 161,892 bridges out of a total 600,905 existing bridges classify as deficient [2]. The 
Engineers Australia Report Card 2000 [3] gives Australia's bridges a rating of 'poor' and has mentioned major deficiencies in state and local bridges that will be exacerbated by increased load limits. A similar situation is found in Japan [4]. To combat this aging infrastructure, rather than replacing entire bridges, municipalities often seek for proper retrofit solutions that can extend bridge fatigue life.

The conventional method of repairing aging metallic bridges often involves bulky and heavy plates that are difficult to attach and are prone to fatigue of their own. Carbon fiber reinforced polymer (CFRP) materials have been used for many retrofit solutions due to their high strengthto-weight ratio, high corrosion resistance and excellent fatigue performance. By using prestressed CFRP material, a larger portion of the material strength is used, resulting in higher yielding and ultimate load capacity of the strengthened elements (e.g., [5,6]). As far as fatigue strengthening is concerned, several experimental studies have shown the effectiveness of using externally applied CFRP plates to reinforce damaged metallic members subjected to fatigue loading. Some studies have used pre-stressed CFRP plates and have shown a substantial increase in the service life of the defective element up to 20 times (e.g., [7-13]), and in some cases, fatigue crack growth was arrested completely [14,15]. Nevertheless, these studies have used an artificial initial crack, thereby neglecting the time required for crack initiation. With the inclusion of an artificial crack, the CFRP material only acts to lengthen the time for stable crack propagation by reducing the effective stress intensity factor (SIF) of the existing crack. However, in reality, many existing metallic bridge members do not contain existing cracks, but rather are nearing their design fatigue life wherein crack initiation is approaching.

This study provides an overview of an innovative retrofit solution applied to a 120-year-old bridge in Münchenstein, Switzerland. Strengthening metallic structures using externally bonded CFRP plates has attracted a lot of research attention in recent years; however, it suffers from several drawbacks mainly related to the metal-to-CFRP bond layer. The effect of high temperature, humidity and fatigue loading on the bond between CFRP plate and metallic substrate are of concern [15]. Moreover, bonding CFRP to unsmooth metallic surfaces (e.g., riveted or corroded surfaces) is not possible. Additionally, externally bonding CFRP plates to wrought iron members is not recommended, due to the unknown interlaminar fatigue strength [16]. In this paper, a new system of un-bonded CFRP strengthening is presented wherein conventional gluing and bonding of the CFRP to the existing steel members is not required. A method based on the constant life diagram (CLD) is proposed for predicting the minimum CFRP pre-stress level required to prevent fatigue crack initiation in metallic girders.

The paper begins by describing background related to the CLD method, after which strengthening of the Münchenstein bridge is discussed. Following measurements from the wireless sensor network (WSN) system are presented and conclusions given on strengthening of existing bridges using the new PUR system. 


\subsubsection{Theory}

\subsubsection{Constant life diagrams (CLDs)}

CLDs are used to demonstrate the combined effect of stress range, mean stress level and material properties. CLDs can foresee the fatigue life of metals at different mean stress levels.

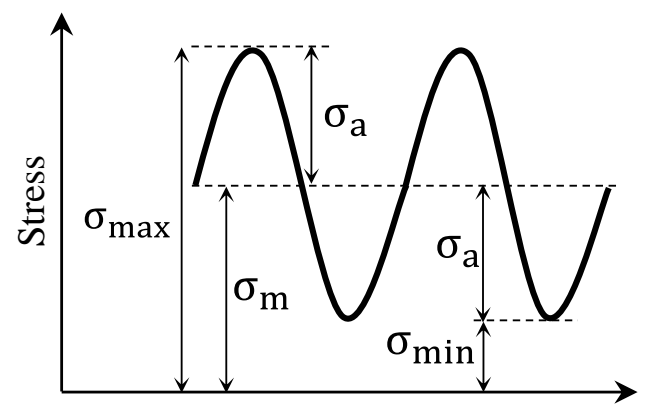

Time

Fig. 3.7.1. A sample stress history.

For a given maximum stress $\left(\sigma_{\max }\right)$ and minimum stress $\left(\sigma_{\min }\right)$ in a sample stress history, as shown in Fig. 3.7.1, the stress amplitude $\left(\sigma_{\mathrm{a}}\right)$ and the mean stress $\left(\sigma_{\mathrm{m}}\right)$ are expressed by

$\sigma_{a}=\frac{\sigma_{\max }-\sigma_{\min }}{2}$

and

$\sigma_{m}=\frac{\sigma_{\max }+\sigma_{\min }}{2}$

with the stress ratio is defined as

$R=\frac{\sigma_{\min }}{\sigma_{\max }}$

Figure 3.7.2 shows a half-plane CLD that can be partitioned into three regions. The right region bounded by $\mathrm{R}=1$ and $\mathrm{R}=0$ is for tension-tension stresses, the middle region bounded by $\mathrm{R}=0$ and $\mathrm{R}= \pm \infty$ is for tension-compression stresses and the left region bounded by $\mathrm{R}= \pm \infty$ and horizontal axis is for compression-compression stresses. Each radial line in the tension-tension region (i.e., $0<\mathrm{R}<1$ ) has a unique symmetric line with respect to the vertical axis in the compressioncompression region with an inverse $\mathrm{R}$ value (e.g., $\mathrm{R}=0.2$ and $\mathrm{R}=10$ ). Ghafoori et al. [16] have described different fatigue criteria for the design of metallic members. Based on the results of many laboratory experiments, the modified-Goodman and the Smith criteria have been recommended for design of ductile metals, such as mild steel and wrought iron, and brittle metals, such as cast iron, respectively. 


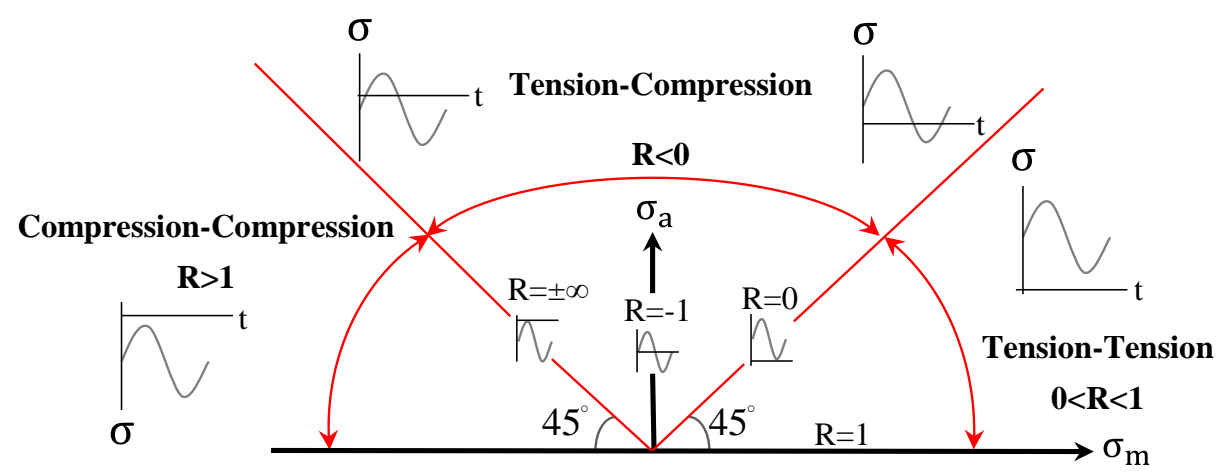

Fig. 3.7.2. CLD can be partitioned into three stress regions of tension-tension when $0<\mathrm{R}<1$, tension-compression when $\mathrm{R}<0$ and compression-compression when $\mathrm{R}>1$.

\subsubsection{Modified Goodman Criterion}

Figure 3.7.3 shows the modified Goodman criterion, the modified Johnson criterion and the yielding lines for $n=1 . S_{y}, S_{u t}$ and $S_{e}$ are the yield stress, ultimate tensile stress and fatigue endurance limit, respectively.

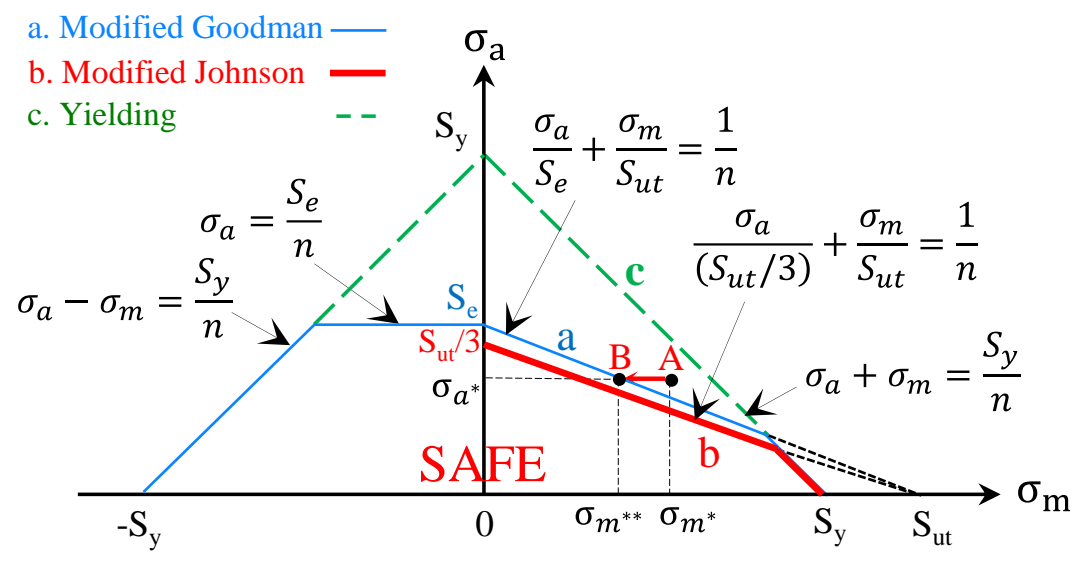

Fig. 3.7.3. CLD representing the modified Goodman and the modified Johnson criteria.

Goodman proposed a straight line through $\sigma_{\mathrm{a}}=\mathrm{S}_{\mathrm{e}}$ and $\sigma_{\mathrm{m}}=\mathrm{S}_{\mathrm{ut}}$, which is a sufficiently conservative approach for the design of ductile metals [16]. The modified Goodman line in the first quadrant (before yielding) is written as

$\frac{\sigma_{a}}{S_{e}}+\frac{\sigma_{m}}{S_{u t}}=\frac{1}{n}$

where $\sigma_{\mathrm{a}}$ and $\sigma_{\mathrm{m}}$ are the stresses at the critical location of the member (e.g., hole edges) and $\mathrm{n}$ is the safety factor. If the fatigue stresses $\left(\sigma_{\mathrm{a}}\right.$ and $\left.\sigma_{\mathrm{m}}\right)$ remain outside of the modified Goodman line, highlighted by blue in Fig. 3.7.3, the member has finite fatigue life, while stresses inside this region have infinite life and are safe against fatigue. The results of lengthy fatigue tests [17] have shown that the fatigue endurance limit is estimated as 
$S_{e}^{\prime}=\left\{\begin{array}{ll}0.5 S_{u t}, & S_{u t} \leq 1400 \mathrm{MPa} \\ 700 \mathrm{MPa}, & S_{u t}>1400 \mathrm{MPa}\end{array}\right.$ for steels

and for wrought irons, the endurance limit can be approximated as

$S_{e}^{\prime}=0.55 S_{u t}$. for wrought irons

The prime sign on $S_{e}^{\prime}$ refers to rotating-beam specimens (i.e., $R=-1$ ) that were prepared very carefully and tested in laboratory conditions. It is not rational to expect the endurance limit of all structural elements to have the same value as that achieved in laboratory conditions. Therefore, Marin [18] developed different parameters to quantify the influence of the size, surface conditions, loading and temperature. The Marin equation was obtained through statistical analysis and is written as

$S_{e}=k_{a} k_{b} k_{c} k_{d} k_{e} S_{e}^{\prime}$,

where $k_{a}, k_{b}, k_{c}, k_{d}$ and $k_{e}$ are, respectively, the surface condition, size, load, temperature and reliability modification factors. $S_{\mathrm{e}}$ is the endurance limit at the critical location of the metallic member in condition and geometry of use. The procedure to calculate the Marin factors is described in Appendix A. Furthermore, notches, holes or defects within members can drastically affect the local stress ranges applied to the detail during fatigue loading. The stress concentration factors are often used to account for defects, holes, or notches. More details about the stress concentration and notch sensitivity factors are given in Appendix B.

\subsubsection{Modified Johnson criterion}

Johnson $[19,20]$ presented a formula in terms of $\mathrm{R}$ and $\sigma_{\max }$ for dimensioning metallic members as

$$
\sigma_{\max }=\frac{S_{u t}}{2-R} . \quad-1 \leq \mathrm{R} \leq 1
$$

Considering the dynamic effects in the case of bridge structures, the elements are subjected to shocks and vibrations due to the moving mass [19-21] commonly called an 'impact'. Johnson has shown that Eq. (3.7.8) is capable of taking into account the effect of both fatigue and impact [19]. Equation (3.7.8) is in terms of $\mathrm{R}$ and $\sigma_{\max }$, but it is possible to formulate it in terms of $\sigma_{\mathrm{a}}$ and $\sigma_{\mathrm{m}}$ and plot it in CLD. Using Eqs. (3.7.1) and (3.7.2), the maximum and minimum stresses are expressed, respectively, as

$$
\begin{gathered}
\sigma_{\max }=\sigma_{m}+\sigma_{a}, \\
\sigma_{\min }=\sigma_{m}-\sigma_{a} .
\end{gathered}
$$

Substituting Eqs. (3.7.3), (3.7.9) and (3.7.10) into Eq. (3.7.8) yields 


$$
\sigma_{a}+\sigma_{m}=\frac{S_{u t}}{2-\frac{\sigma_{m}-\sigma_{a}}{\sigma_{m}+\sigma_{a}}}
$$

After some manipulations, Eq. (3.7.11) can be rewritten as

$$
\frac{\sigma_{a}}{\left(\frac{S_{u t}}{3}\right)}+\frac{\sigma_{m}}{S_{u t}}=1
$$

For design purposes, a safety factor of $n$ may be considered in Eq. (3.7.12) by

$$
\frac{\sigma_{a}}{\left(\frac{S_{u t}}{3}\right)}+\frac{\sigma_{m}}{S_{u t}}=\frac{1}{n} . \quad-1 \leq \mathrm{R} \leq 1
$$

The original Johnson formula does not guard against yielding. The modified Johnson formula, presented in this paper and shown in Fig. 3.7.3, guards against yielding.

\subsubsection{Johnson versus Goodman criterion}

Comparing the Johnson formula presented in Eq. (3.7.13) and the Goodman formula in Eq. (3.7.4), it is seen that by setting the endurance limit to one third of tensile strength $\left(S_{e}=S_{u t} / 3\right)$, the Goodman equation becomes the Johnson equation. Practically, it is possible to use any of these two formulations for design of ductile metallic members. The advantage of using Johnson formula is that it works with the minimum knowledge about the existing metal and needs only the tensile strength $\left(\mathrm{S}_{\mathrm{ut}}\right)$. Although, in general, the modified Goodman criterion is more accurate, it needs much knowledge in order to calculate different Marin factors required for determination of $\mathrm{S}_{\mathrm{e}}$. When sufficient knowledge about the existing metallic girder and its production procedure are known, the modified Goodman formula is recommended for fatigue design. When such information is lacking, the modified Johnson formulation can be used.

\subsubsection{Determination of the minimum CFRP pre-stress level to prevent the initiation of fatigue crack}

Assume that the stresses due to the external fatigue load, $\mathrm{F}$, at the bottom flange of the metallic girder (see Fig. 3.7.4) before strengthening are $\sigma_{m^{*}}$ and $\sigma_{a^{*}}$ and corresponds to point A in Fig. 3.7.3. In this section, the minimum CFRP pre-stress level by which the stresses in metal are shifted from point A ('at risk' zone) to point B ('safe' zone) is determined. Based on Fig. 3.7.3, the magnitude of the required compressive stress in the beam bottom flange to shift the stresses on the Goodman line is written as

$\Delta \sigma_{m}=\sigma_{m^{*}}-\sigma_{m^{* *}}$

where $\sigma_{m^{* *}}$ is obtained by rewriting Eq. (3.7.13) in term of mean stress level as 
$\sigma_{m^{* *}}=\frac{S_{u t}}{n}-\frac{S_{u t} \sigma_{a^{*}}}{S_{e}}$,

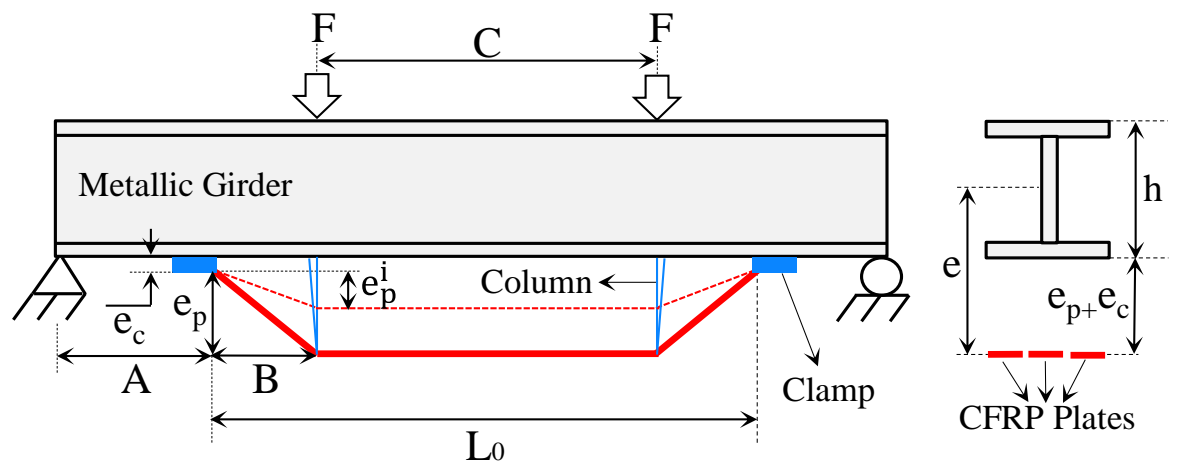

Fig. 3.7.4. Schematic of a metallic girder strengthened by the PUR system.

Note that here it is assumed that the stress range does not change after strengthening. It is because the medium modulus CFRP plates (with a modulus of elasticity less than that of steel) are used; thus, the increase in the stiffness of the metallic member is negligible, and an insignificant decrease in the stress range is expected. Substituting Eq. (3.7.15) into Eq. (3.7.14) gives

$\Delta \sigma_{m}=\sigma_{m^{*}}+\frac{\sigma_{a^{*}}}{S_{e}} S_{u t}-\frac{S_{u t}}{n}$,

where $\Delta \sigma_{m}$ is the minimum required compressive stress to shift the working stresses from point A to point B, as shown in Fig. 3.7.3. The minimum pre-stress force $\left(\mathrm{F}_{\mathrm{pre}}\right)$ in the CFRP plate can be estimated using a cross-section analysis as

$\Delta \sigma_{m}=\frac{e F_{p r e} h}{2 I_{m}}+\frac{F_{\text {pre }}}{A_{m}}$,

where $h, A_{m}$ and $I_{m}$ are the height, the cross-sectional area and the moment of inertia of the metallic beam. $\mathrm{e}$ is the eccentricity between the CFRP plate and the beam neutral axis and is shown in Fig. 3.7.4. Rearranging Eq. (3.7.17) in terms of $F_{\text {pre }}$ gives

$F_{\text {pre }}=\frac{\Delta \sigma_{m}}{\frac{h e}{2 I_{m}}+\frac{1}{A_{m}}}$.

Substituting Eq. (3.7.16) into Eq. (3.7.18) yields to

$\sigma_{\text {pre }}=\frac{\sigma_{m^{*}}+\frac{\sigma_{a^{*}}}{S_{e}} S_{u t}-\frac{S_{u t}}{n}}{\left(\frac{h e}{2 I_{m}}+\frac{1}{A_{m}}\right) A_{p}}$, 
where $\mathrm{A}_{\mathrm{p}}$ is the net cross-sectional area of the CFRP plates and $\sigma_{\text {pre }}$ is the required CFRP prestress to have an infinite fatigue life for the metal. If the same procedure is implemented using the Johnson failure criterion, it would result in

$\sigma_{p r e}=\frac{\sigma_{m^{*}}+3 \sigma_{a^{*}}-\frac{S_{u t}}{n}}{\left(\frac{h e}{2 I_{m}}+\frac{1}{A_{m}}\right) A_{p}}$

Based on the Palmgren-Miner linear damage accumulation rule, when accumulated damage is lower than unity, fatigue failure does not occur. Thus, the overall accumulated damage before and after strengthening shall remain lower than unity as

$\mathrm{D}=\sum \frac{\mathrm{n}_{\mathrm{i}}}{\mathrm{N}_{\mathrm{i}}}=\sum \frac{n_{i}^{b s}}{N_{i}^{b s}}+\sum \frac{n_{i}^{a s}}{N_{i}^{a s}=\infty}=\sum \frac{n_{i}^{b s}}{N_{i}^{b s}}<1$,

where $\mathrm{N}_{\mathrm{i}}$ and $\mathrm{n}_{\mathrm{i}}$ are the number of cycles to failure and the applied number of cycles both at stress level $\sigma_{\mathrm{i}}$, respectively. $\mathrm{D}$ is the overall accumulated damage. Subscripts 'bs' and 'as' refer to 'before strengthening' and 'after strengthening', respectively. Since the strengthening is performed prior to crack initiation, and the applied level of pre-stress is sufficient to shift the stresses into the infinite fatigue life range, knowledge of prior traffic loading on the bridge is irrelevant (refer to [16] for more details). Note that the method described in this paper is only to prevent fatigue crack initiation. However, when the bridge element has already cracked (prior to strengthening), a fracture mechanics based model that has been proposed by Ghafoori et al. [1415] can be used to determine the required CFRP pre-stressing level needed to arrest the fatigue crack propagation in the metal. Non-destructive testing (NDT) inspections can provide evidences of the state of bridge elements, and help bridge authorities to choose the right strengthening scheme.

\subsubsection{Determination of the required eccentricity}

From Section 2.5, the basic idea in this type of strengthening is that by applying a pre-stress force to an existing metallic detail, the mean stress level is reduced so that the life of the detail is increased to infinity. The required pre-stress force can be provided by means of traditional or advanced strengthening materials. As an example for traditional pre-stressing techniques, the use of galvanized greased HDPE sheathed strands offers a good corrosion protection and is capable

to provide sufficient compressive stress in the metallic detail. As an advanced pre-stressing technique, CFRP plates were used for strengthening of Münchenstein Bridge, since they are light and have excellent fatigue and corrosion resistance. Note that the strengthening elements shall be chosen to be as light as possible to have little effect on the structure dead weight. Any increase in weight results in an increased mean stress level that is contradictory to the basic idea behind the presented strengthening method (i.e., reducing the mean stress level).

This section describes a method to approximate the required eccentricity between the CFRP plate and the beam bottom flange to achieve the pre-stress level obtained in section 2.5. Assume a 
metallic girder as shown in Fig. 3.7.4. At the beginning of the strengthening, the CFRP plates are placed and tightened into the friction clamps without any tension. Due to the self-weight of the CFRP plates, they are deflected slightly downward and have an initial eccentricity of $e_{p}^{i}$ from the line connecting the two clamps. The initial eccentricity between the CFRP plate and beam bottom flange is equal to $e_{c}+e_{p}^{i}$, where $e_{c}$ is the height of the clamp. Using a jack, the eccentricity is increased from the initial value of $\mathrm{e}_{\mathrm{p}}^{\mathrm{i}}$ to $\mathrm{e}_{\mathrm{p}}$; therefore, it increases the CFRP pre-stress level to $\sigma_{\text {pre. }}$ The initial lengths of the CFRP plates are estimated as

$L_{i}=C+2 \sqrt{B^{2}+e_{p}^{i^{2}}}$

The final lengths of the CFRP plates at an eccentricity of $e_{p}$ are

$L_{f}=C+2 \sqrt{B^{2}+e_{p}^{2}}$.

When deriving Eq. (3.7.22.b), the upward deflection of the metallic girder is assumed to be negligible. This assumption is reasonable when the cross-sectional dimensions of the beam are much bigger than those of the CFRP plates, which is valid for most existing bridge girders. Based on Eqs. (3.7.22.a) and (3.7.22.b), the imposed stress on the CFRP plates at the eccentricity of $e_{p}$ is

$\sigma_{p r e}=E_{p} \frac{\sqrt{B^{2}+e_{p}^{2}}-\sqrt{B^{2}+e_{p}^{i^{2}}}}{0.5 C+\sqrt{B^{2}+e_{p}^{i^{2}}}}$

In contrast, the minimum required pre-stress in the CFRP plates to have an infinite fatigue life based on the Goodman failure criterion was obtained in Eq. (3.7.19). Equating Eq. (3.7.23) with Eq. (3.7.19) will result in a nonlinear equation in terms of $e_{p}$ as

$\frac{\sigma_{m^{*}}+\frac{\sigma_{a^{*}}}{S_{e}} S_{u t}-\frac{S_{u t}}{n}}{\frac{h\left(e_{p}+e_{c}+0.5 h\right)}{2 I_{m}}+\frac{1}{A_{m}}}=A_{p} E_{p} \frac{\sqrt{B^{2}+e_{p}^{2}}-\sqrt{B^{2}+e_{p}^{i^{2}}}}{0.5 C+\sqrt{B^{2}+e_{p}^{i^{2}}}}$.

The magnitude of the eccentricity can be found by numerically solving Eq. (3.7.24) in terms of $\mathrm{e}_{\mathrm{p}}$. The same procedure can be implemented to find the required eccentricity based on the Johnson criterion by equating Eq. (3.7.23) with Eq. (3.7.20), which yields 
$\frac{\sigma_{m^{*}}+3 \sigma_{a^{*}}-\frac{S_{u t}}{n}}{\frac{h\left(e_{p}+e_{c}+0.5 h\right)}{2 I_{m}}+\frac{1}{A_{m}}}=A_{p} E_{p} \frac{\sqrt{B^{2}+e_{p}^{2}}-\sqrt{B^{2}+e_{p}^{i^{2}}}}{0.5 C+\sqrt{B^{2}+e_{p}^{i^{2}}}}$.

When the ratio of $e_{p} / B$ is small and close to zero $\left(e_{p} / B \rightarrow 0\right)$, the following approximation can be used

$\lim _{\frac{e_{p}}{B \rightarrow 0}}\left(\sqrt{B^{2}+e_{p}^{2}}\right)=B \lim _{\frac{e_{p}}{B} \rightarrow 0}\left(\sqrt{1+\left(\frac{e_{p}}{B}\right)^{2}}\right)=B+\frac{e_{p}^{2}}{2 B}$

Substituting Eq. (3.7.26) into Eq. (3.7.25) results in

$\frac{\sigma_{m^{*}}+3 \sigma_{a^{*}}-\frac{S_{u t}}{n}}{\frac{h\left(e_{p}+e_{c}+0.5 h\right)}{2 I_{m}}+\frac{1}{A_{m}}}=A_{p} E_{p} \frac{B+\frac{e_{p}^{2}}{2 B}-\sqrt{B^{2}+e_{p}^{i^{2}}}}{0.5 C+\sqrt{B^{2}+e_{p}^{i^{2}}}}$.

Equation (27) is a third order polynomial in term of $\mathrm{e}_{\mathrm{p}}$ and can be written as

$\left(\frac{h}{4 I_{m} B}\right) e_{p}^{3}+\frac{1}{2 B}\left(\frac{h e_{c}+0.5 h^{2}}{2 I_{m}}+\frac{1}{A_{m}}\right) e_{p}^{2}+\frac{h}{2 I_{m}}\left(B-\sqrt{B^{2}+e_{p}^{i^{2}}}\right) e_{p}=\gamma$,

where

$$
\begin{aligned}
\gamma=\left(\sigma_{m^{*}}+3 \sigma_{a^{*}}-\frac{S_{u t}}{n}\right)\left(\frac{0.5 C+\sqrt{B^{2}+e_{p}^{i^{2}}}}{A_{p} E_{p}}\right) \\
+\left(\frac{h e_{c}+0.5 h^{2}}{2 I_{m}}+\frac{1}{A_{m}}\right)\left(\sqrt{B^{2}+e_{p}^{i^{2}}}-B\right) .
\end{aligned}
$$

The magnitude of $e_{\mathrm{p}}$ can be approximated by solving the third order polynomial obtained in Eq. (3.7.28).

\subsubsection{Strengthening of the Münchenstein Railway Bridge}

\subsubsection{History of the bridge}

The Münchenstein Bridge was constructed in 1875 by G. Eiffel, who later built the Eiffel Tower in Paris. The bridge is located near Basel City over the river Birs in Switzerland. In 1891, after 15 years of service, the bridge suddenly collapsed when a passenger train was passing across it. The disaster took the lives of 73 passengers [22] and is historically the worst railway accident ever in Switzerland. The results of investigations by Prof. L. Tetmajer, the first director of Empa, which 
was commissioned to investigate this catastrophe, revealed that Euler's formula for buckling had to be modified for slender bars. A single-span riveted bridge was then constructed in 1892, as a replacement for the collapsed one. The bridge, as shown in Figs. 3.7.5.a and 3.7.5.b, consists of 10 frames and was constructed approximately $5 \mathrm{~m}$ above the water level. The total length of the bridge is approximately $45.2 \mathrm{~m}$. The bridge is subjected daily to both passenger and freight trains.

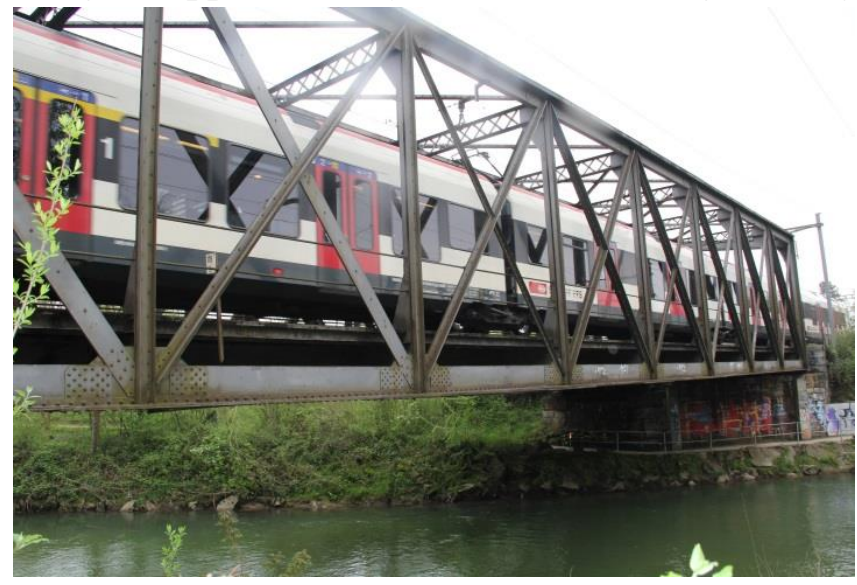

(a)

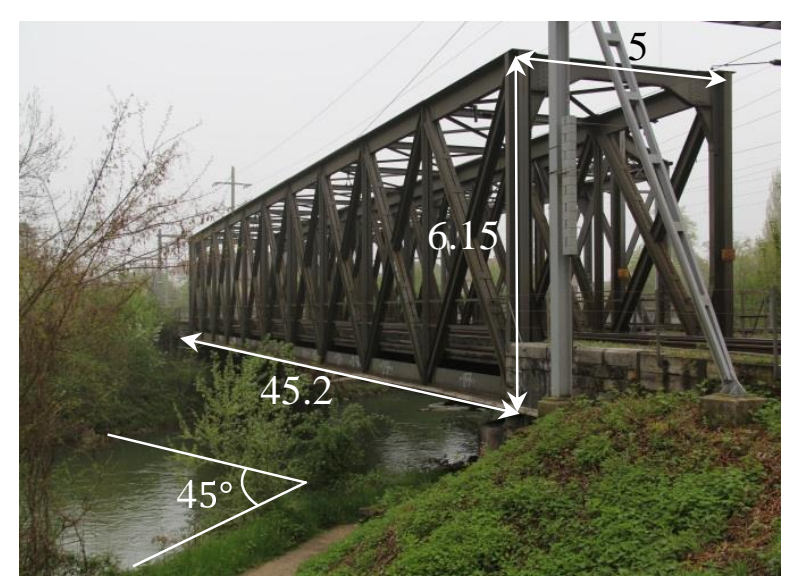

(b)

Fig. 3.7.5. Münchenstein railway bridge (a) subjected to an $S 3$ train, (b) consists of 10 panels with the total length of $45.2 \mathrm{~m}$, width of $5 \mathrm{~m}$ and height of $6.15 \mathrm{~m}$, built on a 45-degrees skew.

\subsubsection{FE modeling of the bridge}

A finite element (FE) model of the bridge was created and analyzed using ABAQUS [23]. The model geometry is based on the construction documents of the Münchenstein Bridge. The bridge consists of two main girders connected by various cross-beams, stringers and lateral bracings, as shown in Fig. 3.7.6.

\subsection{Geometry, mesh, boundary conditions and loading}

The existing bridge supports are skewed at nearly 45 degrees, creating a singly symmetric geometry. Figure 3.7.6.a shows the basic bridge geometry. Figure 3.7.6.b shows a schematic view from the bridge longitudinal direction, and Fig. 3.7.6.c depicts the dimensions of cross-beams. Four-node linear shell elements modeled all geometries within the connection regions. By using shell elements within the connection regions, a more realistic representation of the connection rigidity and subsequent force distribution can be obtained. Additionally, using shell elements, the localized stress distributions and concentrations resulting from local geometric deformations can be determined. Outside the connection regions, beam elements were used to reduce the computational expense. The global boundary conditions of the bridge model simulate the actual support conditions of the constructed bridge. The construction documents indicate that the bridge is supported simply with pin connections on one end and simple bearing rollers on the other, which allow longitudinal translation. Sequences of dynamically applied loads were used to take into account the dynamic behavior of the bridge due to the inertia and vibrations produced by the previous axles. Rayleigh damping was used to consider the effects of damping on the bridge. The 
vertical loads corresponding to individual axle weights were activated and deactivated in series and at different time steps, simulating a moving line load. More details about techniques used for modeling of this bridge can be found in [21].

\subsection{Verification of the results}

To verify the accuracy of the FE model, the strain at different locations of the Münchenstein Bridge was measured and compared with the results of the FE modeling. The measurements were conducted on the second cross-beam from the support side (see Fig. 3.7.6.a). J1 in Fig. 3.7.7 shows the position of the magnetic strain gauge that was mounted at nearly the mid-span of the cross-beam. Figure 3.7.7 compares the strain obtained from the FE results and the on-site measurements when the bridge is subjected to the S3 train. The S3 train is a passenger train with the load model shown in Fig. 3.7.8.a.

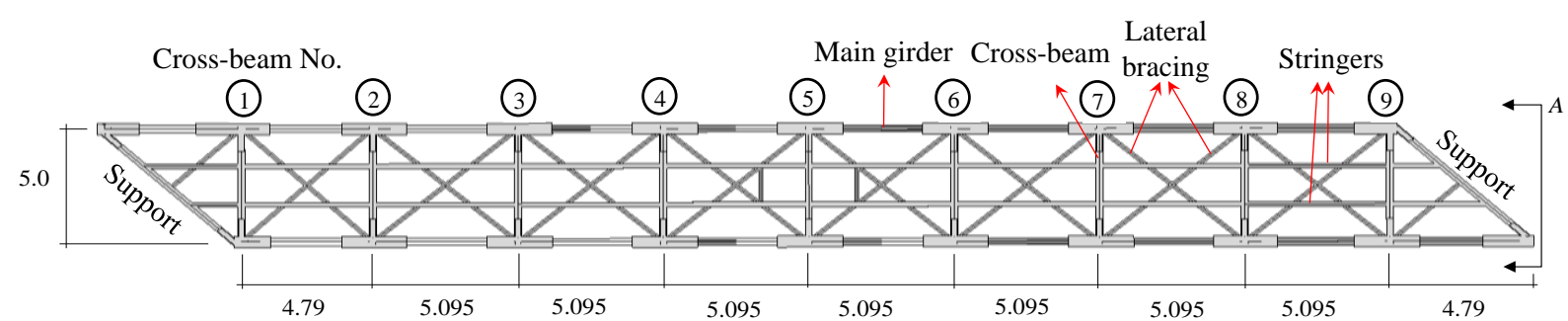

(a)

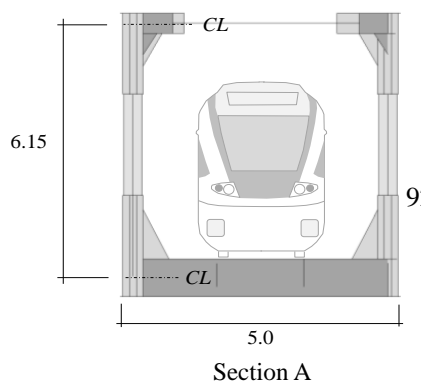

(b)

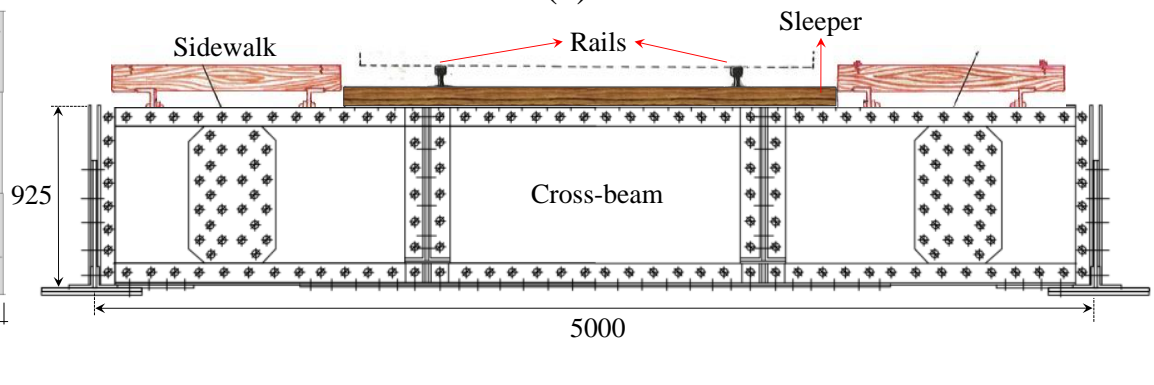

(c)

Fig. 3.7.6. (a) The basic bridge geometry, (b) schematic view from the bridge longitudinal direction (dimensions in $\mathrm{m}$ ) and (c) dimensions of the crossbeams in $\mathrm{mm}$.
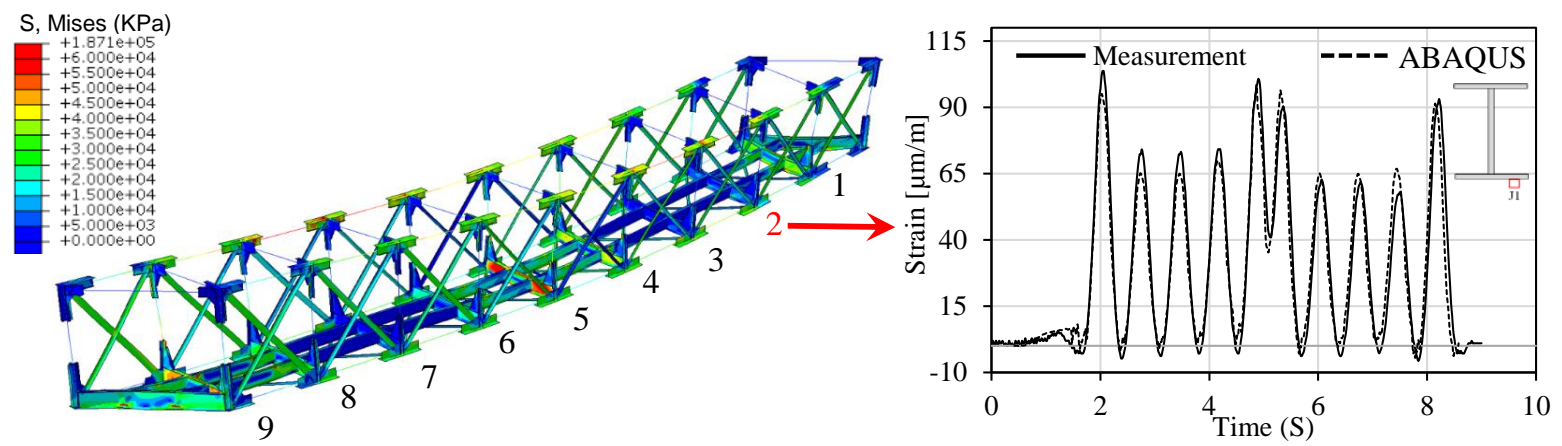

Fig. 3.7.7. Comparison between strains obtained from the FE model and the on-site measurements due to the passage of an $\mathrm{S} 3$ train. 
Based on the data provided by Swiss Federal Railways (SBB), Q=100 kN for an empty train, and $\mathrm{Q}=130.5 \mathrm{kN}$ for a full passenger train. An empty train was assumed for the loading in the FE model due to on-site observations of the passenger occupancy. The S3 train has two units; the first and the last axles of each unit are heavier than the central axle load (see Fig. 8.a). As shown by the curves in Fig. 3.7.7, there are only ten peaks in the deformation history for twenty axles because the axles are close to each other $(2.7 \mathrm{~m})$, and they behave as a single entity. In general, the FE model is in good agreement with the measurements. Some differences in the magnitude of peaks could be due to the unknown level of passenger occupancy of the train. More details about the FE modeling and verifications of the results can be found in [21]. Based on [21], the crossbeams are the most fatigue prone portions of the bridge; therefore, because they are two of the most fatigue prone areas, the fourth and the fifth cross-beams are selected to be strengthened using the PUR system (see Fig. 3.7.7).

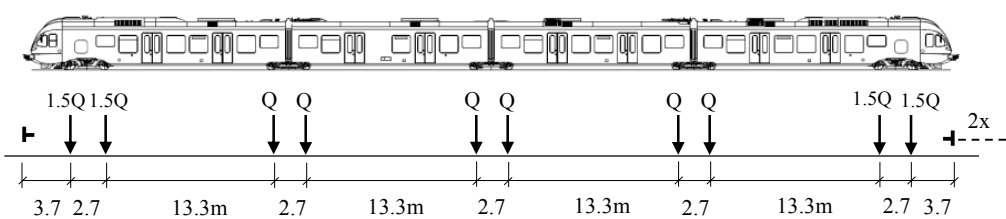

(a)

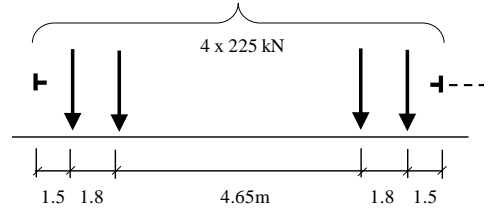

(b)

Fig. 3.7.8. (a) The S3 passenger train load model and (b) the D4 freight train load model.

\subsubsection{Materials and equipment}

The bridge was constructed out of wrought iron. Based on the bridge documents, the Young's modulus, yielding and ultimate strength are $200 \mathrm{GPa}, 220 \mathrm{MPa}$ and $320 \mathrm{MPa}$, respectively. The CFRP plates were of type 150/2000 (provided by the S\&P Company AG, Switzerland) with a width of $50 \mathrm{~mm}$ and a thickness of $1.2 \mathrm{~mm}$. Based on the supplier test data, the CFRP plates had an elastic modulus of 167.2 $\mathrm{GPa}$ and a tensile strength of 2,710 $\mathrm{MPa}$. To measure the strain in the CFRP plates, one strain gauge was bonded to the middle of each plate. The bonded strain gauges were of type 6/120 LY16 with a k-factor of $2.06 \pm 1$ and an electric resistance of $120 \Omega \pm 0.35 \%$. Magnetic strain gauges were used to measure the strain on the bottom flange of the metallic girders. The magnetic strain gauges were of type FGMH-1 (CBF-6) [24] with a k-factor of $2.02 \pm$ 2 and an electric resistance of $120 \Omega \pm 0.5 \%$. To measure the thickness of the anti-corrosion paints on the bridge members, a coating thickness gauge system of type 'Dualscope MP0R' was used. The electronic modules of the WSN monitoring system, including the 8-channel sensor and base station nodes, were provided by Decentlab GmbH.

\subsubsection{Fatigue properties}

To use the modified Goodman criterion, the modified fatigue endurance limit should first be calculated. Based on Eq. (3.7.5), the fatigue endurance limit is calculated to be $\mathrm{S}_{\mathrm{e}}^{\prime}=176 \mathrm{MPa}$. In Appendix C, different Marin coefficients were evaluated for the case of the cross-beams of the bridge, which resulted in $S_{e}=110.3 \mathrm{MPa}$. The stress-concentration factor ( $\mathrm{SCF}$ ) due to holes and 
rivets inside the holes with diameters $\mathrm{d}=23 \mathrm{~mm}$ (see Fig. 3.7.B.1) and a notch ratio of $\mathrm{d} / \mathrm{w}=0.184$ is estimated to be $\mathrm{k}_{\mathrm{t}}=2.48$ (see Appendix B). The notch sensitivity factor for transverse holes (see Table 3.7.B.1) is $\sqrt{a}=0.544$; thus, a notch sensitivity parameter $\mathrm{q}=0.86$ based on Eq. (3.7.B.2) is obtained. Consequently, the fatigue SCF from Eq. (3.7.B.2) is $\mathrm{k}_{\mathrm{f}}=2.27$. Therefore, the maximum stress at the edge of the hole, $\sigma^{\mathrm{h}}$, is written in terms of the remote stress, $\sigma^{\infty}$, using Eq. (3.7.B.1)

$\sigma^{h}=2.27\left(\frac{125}{125-23}\right) \sigma^{\infty}=2.78 \sigma^{\infty}$

\subsubsection{Laboratory tests}

Prior to the application of the PUR system on the bridge, the system was subjected to different loading patterns to examine the static and fatigue performance [16]. The fatigue tests in [16] were arranged such that the accuracy of the analytical method described in Section 2 is experimentally investigated. A total of four identical steel beams were tested, including one un-strengthened beam and three strengthened beams, in a modified staircase method. All beams were tested using a symmetric four-point bending set-up with a span length of $5 \mathrm{~m}$. Two small holes were drilled on bottom flange at mid-span of each beam to create stress concentrations to initiate fatigue cracks while additionally simulating the effect of rivet holes in riveted beams.

The control beam was subjected to a fatigue load range of $\mathrm{F}=2.5-68 \mathrm{kN}$. A fatigue crack was detected at $\mathrm{N}=600,000$ cycles and the cyclic loading was stopped. A beam similar to the control beam was prepared and strengthened by the trapezoidal PUR system with $30 \%$ CFRP pre-stress. After strengthening, the beam was subjected to a similar load range as the control beam and survived 2,000,000 cycles. Since no crack was detected, the pre-stress level was reduced to $22 \%$ and 4,000,000 cycles were applied. No fatigue crack was identified. Again, the CFRP pre-stress level was decreased to $14 \%$ and after 1,200,000 cycles, a fatigue crack was found at the hole location. The minimum required pre-stress level determined from the CLD analysis corresponded well with observed experimental results [16]. Due to inherent scatter in fatigue lives, two additional beams were prepared, strengthened and tested with an identical experimental procedure as just described. Moreover, the developed PUR system performed well during the fatigue testing, surviving more than 33,000,000 cycles without any damage or sliding in the friction clamps. More details about experimental program and the test results can be found in [16].

\subsubsection{Bridge strengthening and measurements}

The average thickness of the anti-corrosion coating at the cross-beam locations was measured to be approximately $0.5 \mathrm{~mm}$. If a bonded CFRP system is used, this surface would have to be cleaned and all coatings that were accumulated over the bridge life would need to be removed. In addition, these anti-corrosion paints are often toxic and have to be treated carefully during removal. In contrast, the presented non-bonded retrofit system does not require any surface preparation, making the strengthening procedure easy and fast. Based on the Swisscode (SIA 
[25]), a freight train load model D4 (see Fig. 3.7.8.b) has to be used for fatigue verification. Applying the D4 load model as the live load and also considering the dead load in the FE model, the stresses at the bottom flanges of the cross-beams were obtained. Applying the SCF obtained from Eq. (3.7.25) would result in $\sigma_{m^{*}}$ and $\sigma_{a^{*}}$ stresses of 82.5 $\mathrm{MPa}$ and 91.1 MPa, respectively, in bottom flange of the fifth cross-beam. Furthermore, considering Figs. 3.7.4 and 3.7.6, the following parameters were used for the strengthening of the fifth cross-beam:

$A=825 \mathrm{~mm}, B=825 \mathrm{~mm}, C=1700 \mathrm{~mm}, L_{0}=3350 \mathrm{~mm}, e_{p}^{i}=77 \mathrm{~mm}$,

$\mathrm{e}_{\mathrm{c}}=55 \mathrm{~mm}, \mathrm{~h}=925 \mathrm{~mm}$.

Figure 3.7.9 demonstrates the CFRP pre-stress level in terms of the eccentricity, $\mathrm{e}_{\mathrm{p}}$, for different initial eccentricity values, $e_{p}^{i}$, using Eq. (3.7.23). Based on Eq. (3.7.20), considering a safety factor of $n=1.04$, a pre-stress level of approximately $34.5 \%$ is determined for strengthening using the Johnson criterion. Once the friction clamps were mounted on the cross-beam and the CFRP plates were fixed into the clamps, an initial eccentricity of $e_{p}^{i}=77 \mathrm{~mm}$ was observed. Thus, for an initial value of $e_{p}^{i}=77 \mathrm{~mm}$, an eccentricity of $\mathrm{e}_{\mathrm{p}}=142 \mathrm{~mm}$ was required to gain $34.5 \%$ prestress in CFRP plates. This eccentricity could also be directly found using Eq. (3.7.25). During the on-site strengthening, a jack is used to increase the eccentricity between the CFRP plates and the beam; thus, the CFRP pre-stress level and the magnitude of the compressive stress at the rivet holes increase, as shown in Fig. 3.7.10. The strain on the CFRP plate and the metallic beam are measured using the glued and magnetic strain gauges, respectively. The procedure of prestressing the CFRP plates took approximately 30 minutes, and during this time, trains were crossing the bridge. The two sudden jumps in the stress at the bottom flange of the beam indicate the passage of two passenger trains.

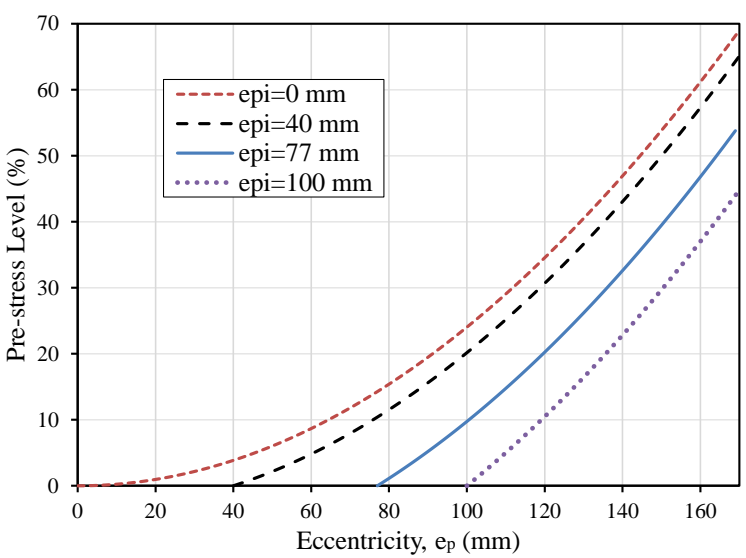

Fig. 3.7.9. The CFRP pre-stress level as a function of the eccentricity, $\mathrm{e}_{\mathrm{p}}$, for different initial eccentricities, $e_{p}^{i}$, (see Fig. 3.7.4).

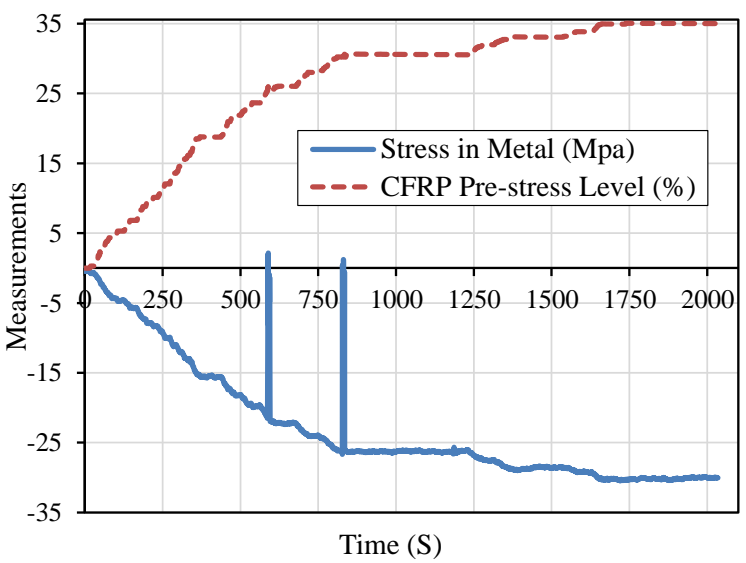

Fig. 3.7.10. As the eccentricity between the CFRP plates and beam increases, the CFRP pre-stress level and the magnitude of the compressive stress at the rivet holes increase. 
Figure 3.7.11 shows the stresses in the flange before and after strengthening in CLD. This figure shows that the modified Goodman and the modified Johnson formulas show very similar fatigue behavior. Note that although calculation of the endurance limit, $S_{e}$, for the Goodman criterion required a lot of knowledge about the cross-beam (described in Appendices A and C), ultimately, the predictions of both criteria are very similar. According to Fig. 3.7.11, the modified Johnson criterion is slightly more conservative than the modified Goodman criterion, and it is used for the design in this paper. In Fig. 3.7.11, it is observed that the stresses are shifted to the safe region based on both the modified Goodman and modified Johnson criteria.

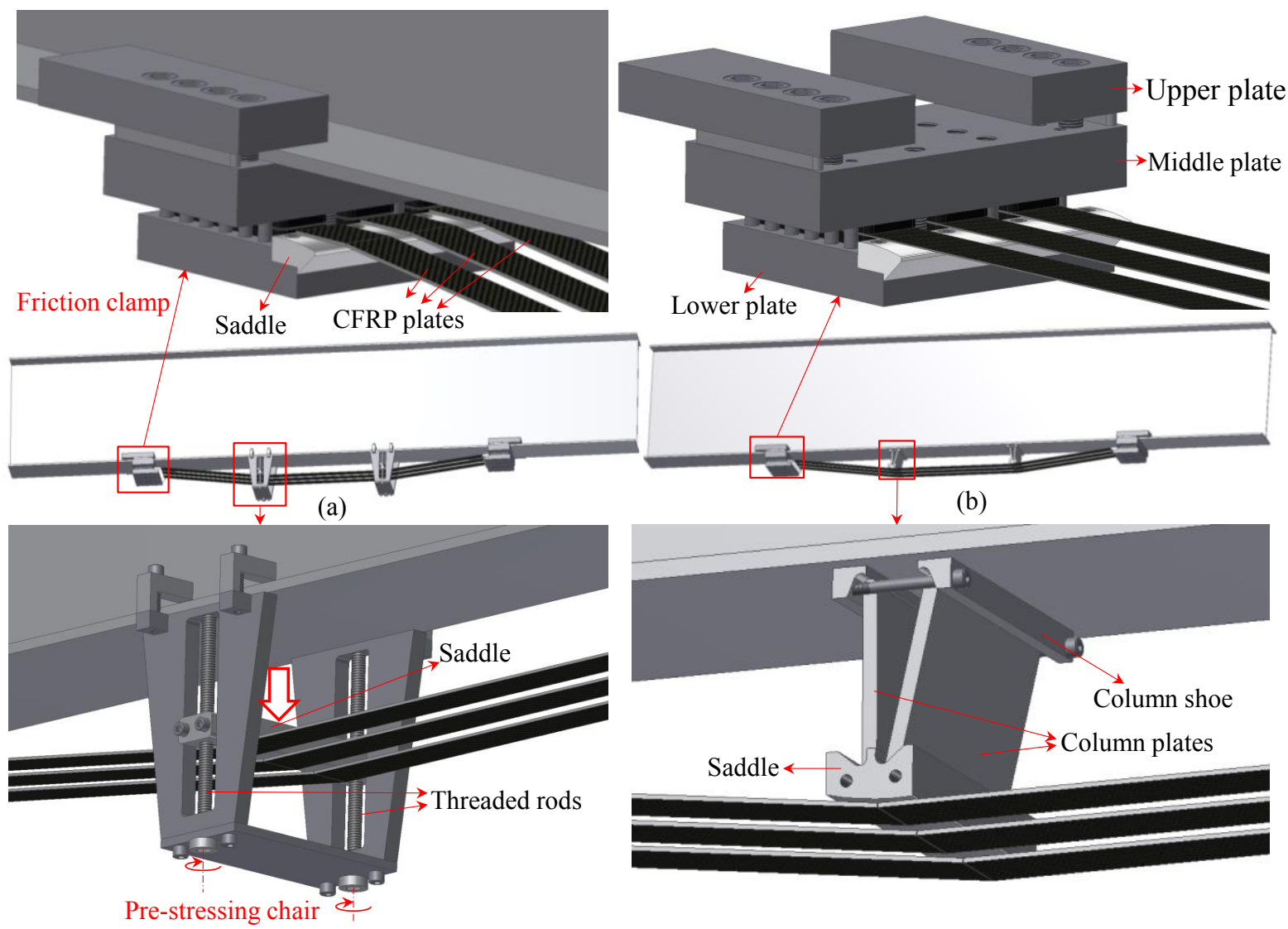

Fig. 3.7.12. Different components of the retrofit system: (a) the pre-stressing chair includes a saddle that pushes the CFRP away from the beam and (b) once the required eccentricity is reached, two column plates are placed between the CFRP plates and the saddle. More details about the design of the trapezoidal PUR system are described in [26].

Figure 3.7.12 schematically shows the different components of the retrofit system. The friction clamp consists of a lower plate, a middle plate and two upper plates. Three CFRP plates are gripped between the lower plate and the middle plate due to the compressive force imposed by the pre-stressed bolts. The lower flange of the beam is also gripped between the middle plate and the upper plate due to the compressive force provided by the pre-stressed bolts. 


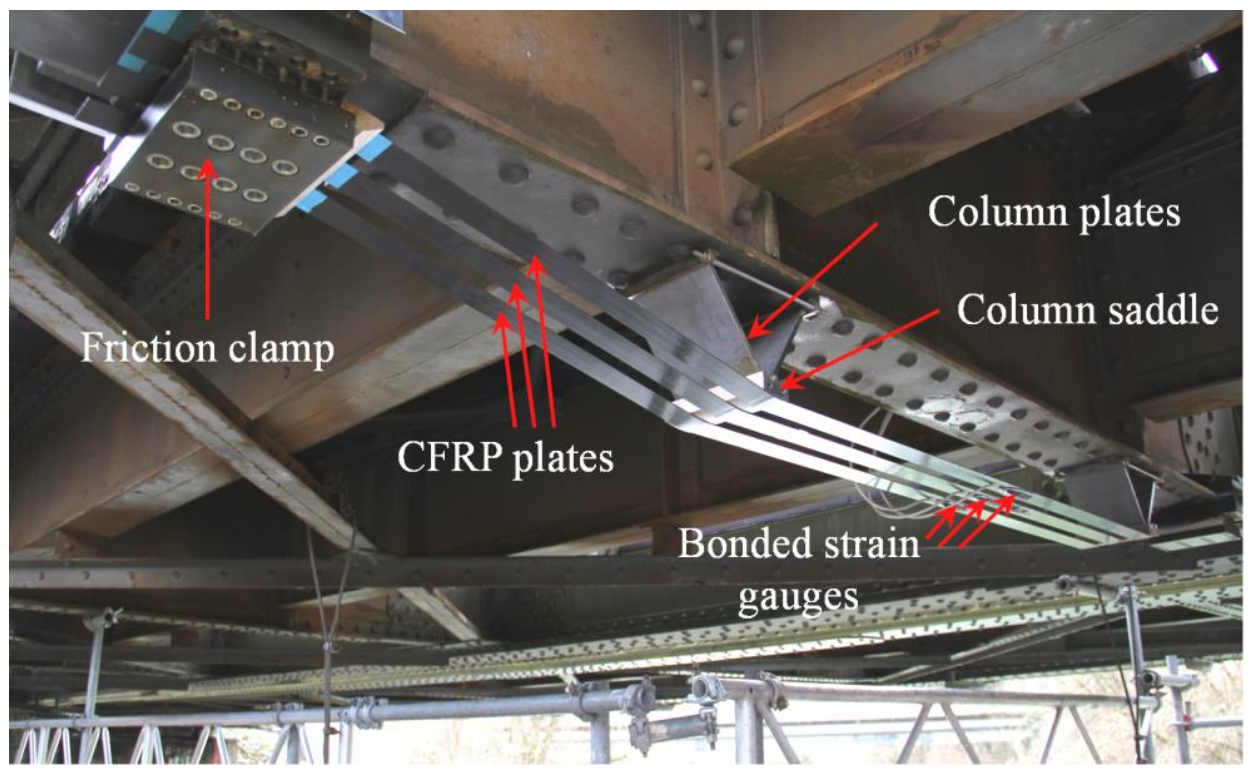

(a)

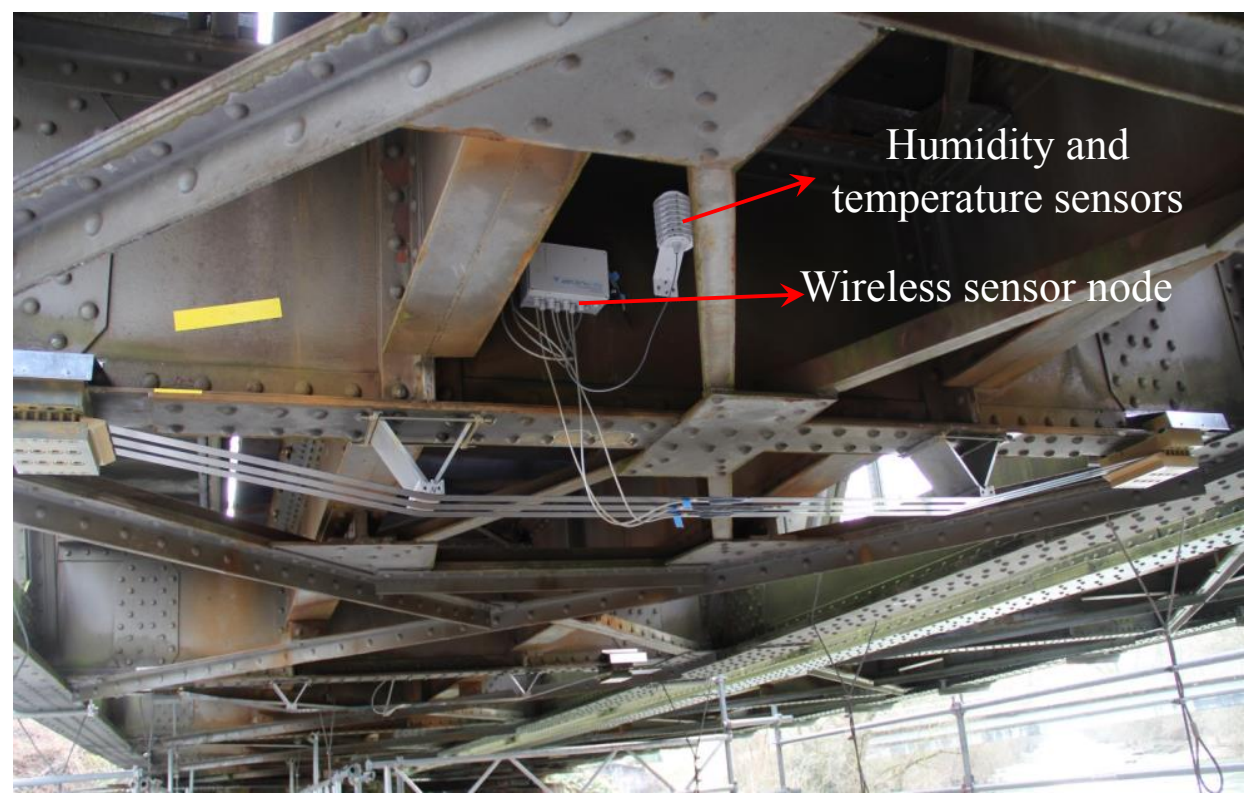

(b)

Fig. 3.7.13. The (a) fourth and (b) fifth strengthened crossbeams. A strain gauge is glued to each CFRP plate and is connected to the WSN system for long-term monitoring of the pre-stress level.

The pre-stressing chair consists of a saddle that is guided along two threaded bars. The position of the saddle with respect to the beam can be adjusted by turning the threaded rods, as shown in Fig. 3.7.12.a. By turning the threaded rods, the saddle moves downward and pushes the CFRP 
plates downward. Once the required eccentricity between the CFRP plates and the beam is achieved, two column plates are inserted between the saddle and the beam and the pre-stressing chair is removed. Each column plate is placed into a column shoe, as shown in Fig. 3.7.12.b. Note that the system does not require any welding or drilling holes in the existing structure. The system can be disassembled and removed from the bridge (if necessary) without any residual effects on the existing bridge.

Figure 3.7.13 shows a view of the fourth and the fifth bridge cross-beams after strengthening by the PUR system. The CFRP plates lie on a saddle at the columns. Note that the system has two types of saddles, as shown in Fig. 3.7.12: one clamp saddle and one column saddle. Both saddles have a smooth surface with low curvature (approximately $200 \mathrm{~mm}$ ) to accommodate the change in longitudinal direction of the CFRP plates. In order to prevent galvanic corrosion at the location of the saddles where steel and CFRP are in direct contact, a thin Teflon tape was applied on the surface of saddles. Teflon tape also reduces the friction between the CFRP plates and the saddles. Moreover, in order to prevent direct contact between the CFRP plates and steel clamp (inside the clamp), a layer of sandpaper was used between each CFRP plate and the steel clamp (inside the

clamp). This is to prevent the damage at the outer surface of the CFRP plate and also to avoid galvanic corrosion between steel and CFRP inside the clamp. More details about the design and development procedure of the trapezoidal PUR system are given in [26]. The bridge is located over a river and the cross-girders of the bridge cannot be reached without scaffolding (protecting the system from vandalism).

The system was developed at Empa and registered as a patent [27]. More details about the design of the friction clamps, columns and saddle will be published in another paper. Figure 3.7.14 shows the stress time-history at the mid-span of the bottom flange of the fifth cross-beam before and after strengthening due to the passage of an S3 passenger train. Note that the dead load is not included in this measurement because the strain gauges are only sensitive to live loads. The amplitude of the fluctuating stresses in the CFRP plates due to train passage is small (approximately 0.7\%). Fig. 3.7.14 shows that the stress range does not change before and after strengthening, which confirms the validity of the assumption made in section 2.6. Note that the bridge is subjected to different types of trains, including passenger and freight trains. The design of the strengthening system was based on a D4 freight train load model because the mean stress level still remains in the tension zone after strengthening (see Fig. 3.7.11).

\subsubsection{WSN technology for long-term monitoring}

In recent years, WSN technology has been used to monitor the health of different types of civil structures [28]. The WSN system offers many attractive features, such as cable-free and easy deployment, which minimize the installation time and cost [29]. To ensure no slip occurs between the CFRP plates and the clamps and also between the friction clamps and the metallic beams, one strain gauge was glued on each CFRP plate, as shown in Figs. 3.7.13. Because strain gauges do not automatically compensate for temperature, for each active strain gauge, a dummy 
strain gauge was used to compensate for the effects of temperature variations. The dummy strain gauges, which are identical to the active strain gauges, were glued to unstrained CFRP plates and placed near the active gauges. To account for the temperature effects, the dummy strain gauges were wired into a Wheatstone bridge on an arm adjacent to the active strain gauge. All of the strain gauges as well as the humidity and temperature sensors were connected to the WSN node. The housing of the WSN node and those of the temperature and humidity sensors, shown in Fig. 3.7.13.b, were equipped with four magnetic footings, which allows for a simple and fast mounting. The WSN system reads the strains, temperature and relative humidity at intervals of 5 minutes and sends the data to a base station, which then sends the data online.

Figure 3.7.15 shows the time history of the on-site temperature and the CFRP pre-stress level for one CFRP plate mounted on the fifth cross-beam of the bridge. The other CFRP plates have almost the same behavior. As the temperature increases, the CFRP pre-stress level increases because the CFRP material has a negligible thermal expansion coefficient in its fiber direction compared to the wrought iron. As shown in Fig. 3.7.15, with an approximately 14 degrees Celsius increase in the ambient temperature, the CFRP pre-stress level increases by approximately $1.3 \%$. Because the WSN reads data at a time interval of 5 minutes, it measures data mostly when there is no train crossing the bridge. However, the sudden sharp jumps that can be observed in the CFRP pre-stress level are due to the passages of trains that are captured by WSN system. The maximum increase in the CFRP pre-stress level due to the passage of trains is approximately $0.7 \%$, which is less than the temperature effect (i.e., $1.3 \%$ ). The change in humidity did not have any considerable influence on the CFRP pre-stress level. The WSN system remains on the bridge to monitor possible pre-stress loss and also to measure the effect of the temperature. The results related to this long-term monitoring will be reported in another paper.

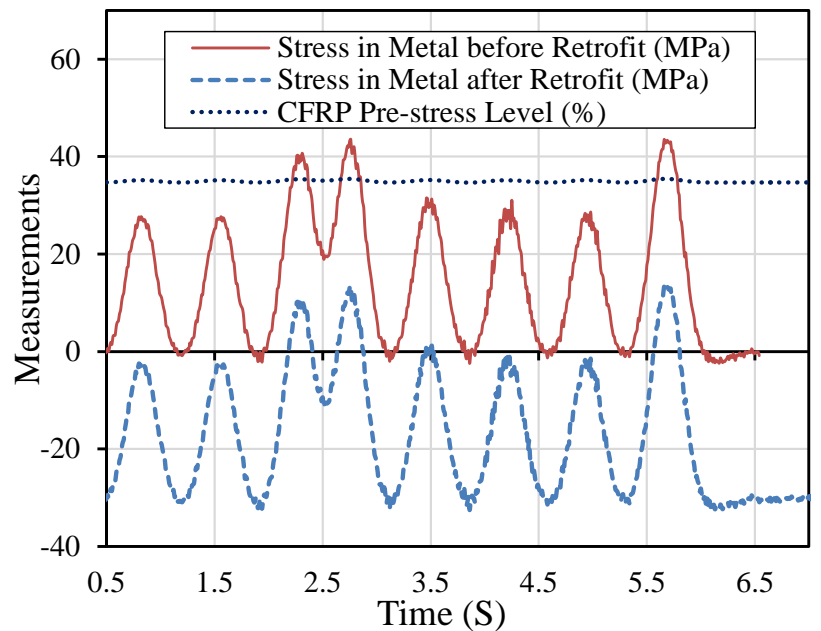

Fig. 3.7.14. Stress at the critical location of the fifth crossbeam due to the passages of an S3 train before and after strengthening.

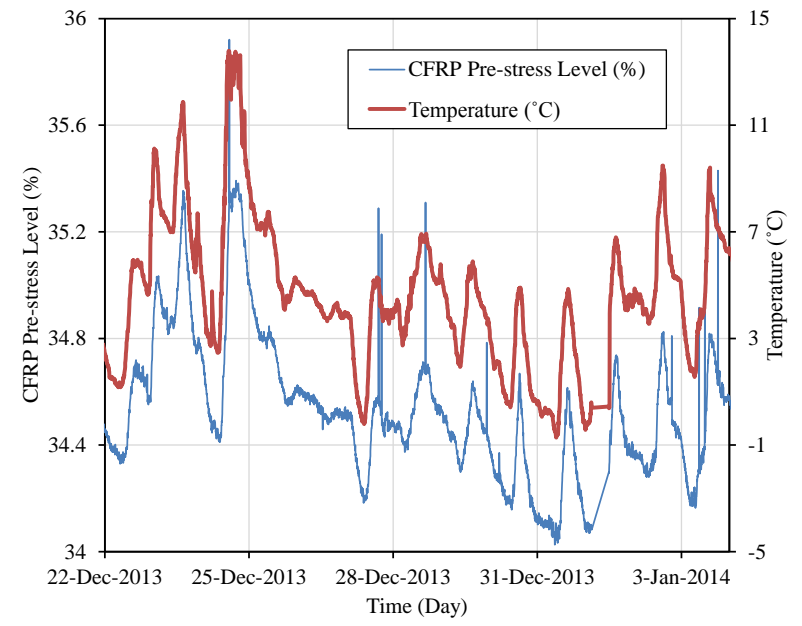

Fig 3.7.15. Time history of the pre-stress level in the CFRP plate and the on-site temperature for a period of 2 weeks obtained by the WSN system. 


\subsubsection{Discussion on the accuracy of the existing codes}

Many structural codes use a routine method for the evaluation of fatigue damage in metallic bridges. In this method, the dominant parameter affecting the fatigue life of a metallic member is the stress range, and the mean stress level does not play a role when both the minimum and maximum stresses are under tension. However, for non-welded components, when the minimum stress is negative, a portion (e.g., 40\% based on Eurocode [30]) of the compressive stress ranges are neglected. Consider points $\mathrm{A}$ and $\mathrm{B}$ in the tension-tension stress region of the CLD shown in Fig. 3.7.16. They have an identical stress range but different mean stress levels. Thus, based on the method suggested in most structural codes, if point A is found to have an infinite fatigue life, point $\mathrm{B}$ with the same stress range but higher mean stress level (lower stress ratio) would also be found to have an infinite fatigue life (equal to the fatigue life at point A). This is because the latter method does not consider the effect of increased mean stress level. However, according to the modified Goodman failure criterion (for ductile metals), point $\mathrm{A}$ is at safe region (infinite fatigue life) and point $\mathrm{B}$ is in the at-risk region (finite fatigue life).

Thus, according to the method suggested in most structural codes, both A and B have similar fatigue susceptibility, but the presented CLD method results in different fatigue susceptibilities for these two stress points. This is because the latter considers the combined effects of the stress range and the mean stress level, however the former is only based on the stress range. The suggested approach in existing structural codes seems to be non-conservative for tension-tension stress patterns with $0<\mathrm{R}<1$. In the case of truss bridges, for example, most of the critical elements are subjected to stress ratios between 0 and unity (i.e., $0<\mathrm{R}<1$ ) for which the accuracy of the methods in existing codes is under question. It is clear that there is a need for an approach that considers both the mean stress level and the stress range for fatigue verification. The modified Goodman and modified Johnson criteria that were presented in this paper consider the combined effects of the stress range, mean stress level and material properties; additionally, these criteria are relatively easy to use.

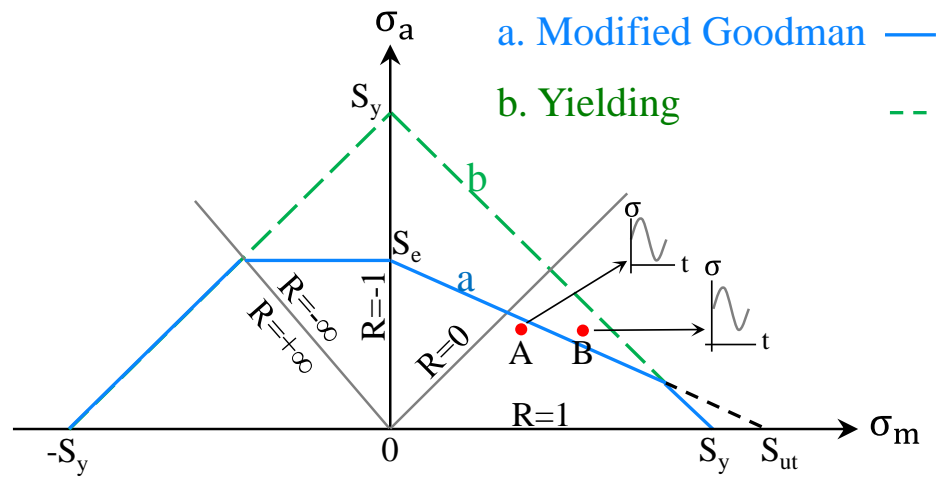

Fig. 3.7.16. A constant fatigue life diagram.

As mentioned earlier, if an endurance limit of one third of the tensile strength $\left(S_{e}=S_{u t} / 3\right)$ is assumed, the Goodman formula turns into the Johnson equation. The modified Johnson criterion 
is recommended when there is not sufficient knowledge about the metallic members to calculate the different factors in the Marin formulation. The presented modified Johnson formula needs only the ultimate tensile strength as the input parameter and offers a simple and straightforward method for design purposes.

\subsubsection{Conclusions}

A pre-stressed, non-bonded CFRP retrofit system was developed and used for fatigue strengthening of a 120-year-old metallic railway bridge in Switzerland. Analytical formulations based on the CLD method were introduced to predict the minimum CFRP pre-stress levels required to prevent fatigue crack initiation in the metal. The following conclusions were determined from the study:

1. By applying a pre-stress force to an existing fatigue-susceptible detail, the mean stress level (and the stress ratio) can be reduced such that the detail is shifted from the finite life regime to the infinite life regime. The method is particularly valuable when the stress history due to prior traffic loading cannot be easily determined, making it difficult to assess which fraction of the detail life has been already consumed based on the Miner's rule.

2. Although the modified Goodman criterion requires extensive knowledge about the materials within the existing metallic girder, it resulted in nearly the same fatigue assessment as that determined by the modified Johnson formula which requires little a-priori material knowledge.

3. Based on many structural codes, the stress range is the main parameter that affects the fatigue life of a metallic member. A major deficiency related to this method is that it does not consider the mean stress effect for stress ratios of $0<\mathrm{R}<1$ (i.e., tension-tension stresses). Both the modified Johnson and the modified Goodman criteria reflect the combined effects of the stress range, mean stress level and material properties. The suggested modified Johnson formula is easy to apply and needs only the ultimate tensile strength as the input parameter, which makes the method suitable for design purposes.

4. Old metallic bridges typically have a thick layer of coating accumulated due to many applications of anti-corrosion paint. This coating is often toxic and has to be treated carefully. The presented un-bonded retrofit system does not require any surface preparation, thereby making the strengthening procedure easy and fast.

5. An analytical method was presented to calculate the required eccentricity between CFRP plates and beam bottom flange to reach a certain amount of CFRP pre-stress.

6. A WSN system was used to monitor the pre-stress level in each CFRP plate as well as the onsite temperature and relative humidity. Due to the low thermal expansion coefficient of the CFRP 
material in the fiber direction compared to the bridge metal, an increase in ambient temperature results in an increase in the stress in the CFRP plates.

\section{Appendix A}

Different modification factors related to the Marin equation are explained in this appendix.

Surface condition modification factor: A rotating-beam sample has a highly polished surface. A surface modification factor is a function of the tensile strength of the actual part and the quality of its surface finish. It is written as [31]

$k_{a}=a S_{u t}^{b}$,

where $\mathrm{a}$ and $\mathrm{b}$ are the two coefficients given in Table 3.7.A.1.

Size modification factor: The size factors for round rotating bars were obtained through curve fitting of experimental results [32]

$k_{b}= \begin{cases}1.24 d^{-0.107}, & 2.79 \leq d \leq 51 \mathrm{~mm} \\ 1.51 d^{-0.157}, & 51<d \leq 254 \mathrm{~mm}\end{cases}$

The size factor presented in the above equation is for the case of rotating bars. For structural members that often do not rotate and have a non-tubular section, the method of effective dimension is used. The effective dimension, $\mathrm{d}_{\mathrm{e}}$, is calculated by calculating the area stressed at 95\% $\left(\mathrm{A}_{0.95 \sigma}\right)$ of the maximum stress to the same area in the rotating-beam samples [33]. Figure 3.7.A. 1 shows $A_{0.95 \sigma}$ and the corresponding effective dimension $d_{e}$ for rectangular and I-beam cross-sections. Once $d_{e}$ is calculated, it can be used in Eq. (3.7.A.2) to find the correct size factor. Note that for the case of axial loading, the size factor is $\mathrm{k}_{\mathrm{b}}=1$.
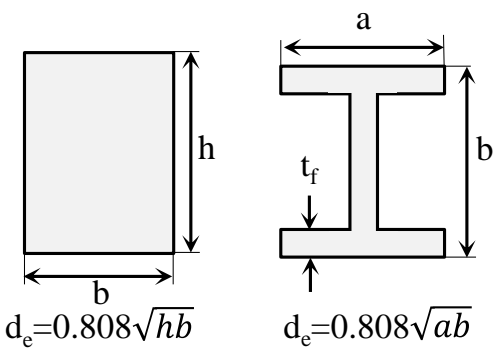

Fig. 3.7.A.1. The effective dimension, $d_{e}$, for rectangular and I-beam cross-sections [33].

Load modification factor: The endurance limit obtained through experimental analysis is dependent on whether the tests were performed with rotational bending, axial tensioncompression or torsion and are estimated for steel and wrought iron using [17] 
$k_{c}=\left\{\begin{array}{lr}1, & \text { bending } \\ 0.85, & \text { axial } \\ 0.59, & \text { torsion }\end{array}\right.$

The average $\mathrm{k}_{\mathrm{c}}$ for axial and torsional loading of cast iron members is estimated to be 0.9 .

Table 3.7.A.1. Coefficients for different surface finishes [31].

\begin{tabular}{|c|c|c|}
\hline $\begin{array}{c}\text { Surface } \\
\text { Finish }\end{array}$ & $\begin{array}{c}\text { Exponent } \\
\mathrm{b}\end{array}$ & $\begin{array}{c}\text { Factor a } \\
\mathrm{S}_{\mathrm{ut}}, \mathrm{MPa}\end{array}$ \\
\hline As-forged & -0.995 & 272 \\
\hline Hot-rolled & -0.718 & 57.7 \\
\hline $\begin{array}{c}\text { Machined / } \\
\text { Cold-drawn }\end{array}$ & -0.265 & 4.51 \\
\hline Ground & -0.085 & 1.58 \\
\hline
\end{tabular}

Table 3.7.A.2. Reliability factors based on the probabilistic analysis with a Gaussian distribution assumption [35].

\begin{tabular}{|c|c|c|}
\hline Reliability & $\mathrm{z}_{\mathrm{a}}$ & $\mathrm{k}_{\mathrm{e}}$ \\
\hline $50 \%$ & 0 & 1.000 \\
\hline $90 \%$ & 1.288 & 0.897 \\
\hline $95 \%$ & 1.645 & 0.868 \\
\hline $99 \%$ & 2.326 & 0.814 \\
\hline $99.9 \%$ & 3.091 & 0.753 \\
\hline $99.99 \%$ & 3.719 & 0.702 \\
\hline
\end{tabular}

Temperature modification factor: When the operating temperature is much higher or lower than room temperature, yielding or brittle failure, respectively, should be the first causes investigated [17]. The following fourth order polynomial, which was obtained by fitting the experimental results at different operation temperatures, is used to determine the temperature factor [34]

$$
k_{d}=0.9877+0.6507\left(10^{-3}\right) T_{c}-0.3414\left(10^{-5}\right) T_{c}^{2}+0.5621\left(10^{-8}\right) T_{c}^{3}-6.246\left(10^{-12}\right) T_{c}^{4}
$$

where $\mathrm{T}_{\mathrm{c}}$ is the temperature in degrees Celsius.

Reliability modification factor: As mentioned earlier, the presented modification factors have been calculated using statistical analysis where the data were highly scattered. Haugen and Wirsching [35] presented a relationship between the standard deviation of endurance limits as 
$k_{e}=1-0.08 z_{a}$

where $\mathrm{z}_{\mathrm{a}}$ is defined through a probabilistic analysis using a Gaussian distribution assumption as shown in Table 3.7.A.2. The table also includes the corresponding reliability factors for each $\mathrm{z}_{\mathrm{a}}$.

\section{Appendix B}

$S C F$ : An SCF, $\mathrm{k}_{\mathrm{t}}$, is defined as the ratio of the actual maximum stress, $\sigma^{h}$, at the edge of a hole to the nominal stress, $\sigma^{0}$, along the section of the hole. Figure 3.7.B.1 shows the SCF of a thin plate with a center hole tension load, where $w$ is the width of plate, $\mathrm{d}$ is the diameter of hole and $\sigma^{\infty}$ is the stress far from the hole. The SCF depends on the geometry of the sample and not the material properties.

Notch sensitivity factor: Some materials are not sensitive to the presence of a notch [17], and a reduced value of $\mathrm{k}_{\mathrm{t}}$ may be used. The maximum stress at a hole $\sigma^{h}$ is expressed by

$\sigma^{h}=k_{f} \sigma^{\infty} \frac{w}{w-d^{\prime}}$

where $\mathrm{k}_{\mathrm{f}}$ (which is a reduced value of $\mathrm{k}_{\mathrm{t}}$ ) is often called the fatigue $\mathrm{SCF}$. Unlike $\mathrm{k}_{\mathrm{t}}$, $\mathrm{k}_{\mathrm{f}}$ depends on both the geometry and the material properties of the part and is defined by

$k_{f}=1+q\left(k_{t}-1\right)$

In Eq. (3.7.B.2), $\mathrm{q}$ is the notch sensitivity parameter and is normally between zero and unity. The Notch-sensitivity is defined as [36]

$q=\frac{1}{1+\frac{\sqrt{a}}{\sqrt{r}}}$

where $\mathrm{r}$ is the radius of the notch and $\sqrt{a}$ is the Neuber constant, which depends on the material properties. The Neuber constant for steels and wrought irons are given in Table 3.7.B.1. It is recommended to use the conservative value of $\mathrm{q}=0.2$ for all grades of cast irons [17]. A more conservative and simple approach to find the fatigue SCF is to simply use $\mathrm{k}_{\mathrm{f}}=\mathrm{k}_{\mathrm{t}}$ for all cases.

The fatigue strength of riveted joints: Yin et al. [37] have tested several joints with various numbers of rivets/bolts in a row and subjected to fatigue loading, as shown in Fig. 3.7.B.2. The experimental results show that for more than four rivets in a line, the fatigue strength of the joints with and without pre-tensioned rivets approaches that of a plate with a center hole. Because the bottom flange of the bridge cross-beams consist of connections with more than 4 rivets in a line (see Fig. 3.7.13), the design of the pre-stress level of the cross-beams in this study was reasonably performed using the free hole assumption, which is independent of any rivet pretension level. Note that in order to easily control the pre-tension level in the joint, Yin et al. [37] 
used pre-tensioned bolts instead of rivets and assumed that both have the same behavior (i.e. similar hole edge defects and pre-tension levels).

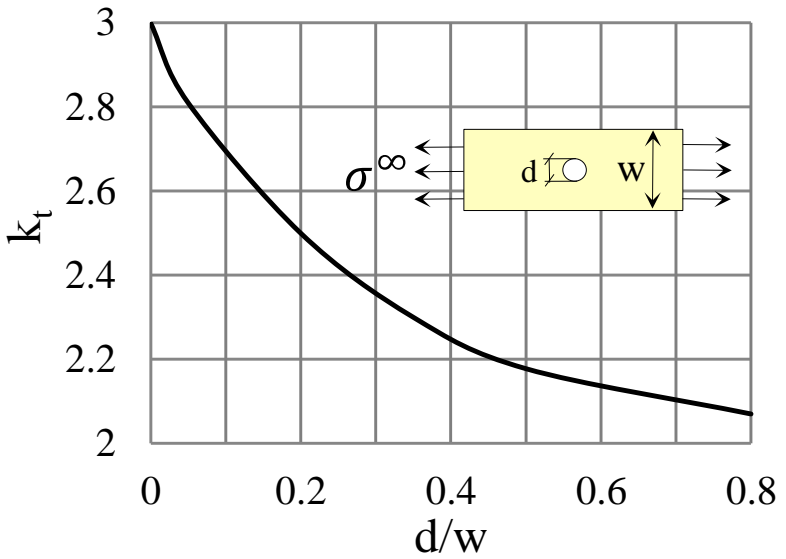

Fig. 3.7.B.1. $\operatorname{SCF}\left(\mathrm{k}_{\mathrm{t}}=\sigma^{\mathrm{h}} / \sigma^{0}\right)$ for a plate with a center hole [17]. The nominal stress is $\sigma^{0}=\sigma^{\infty} /(1-\mathrm{d} / \mathrm{w})$.

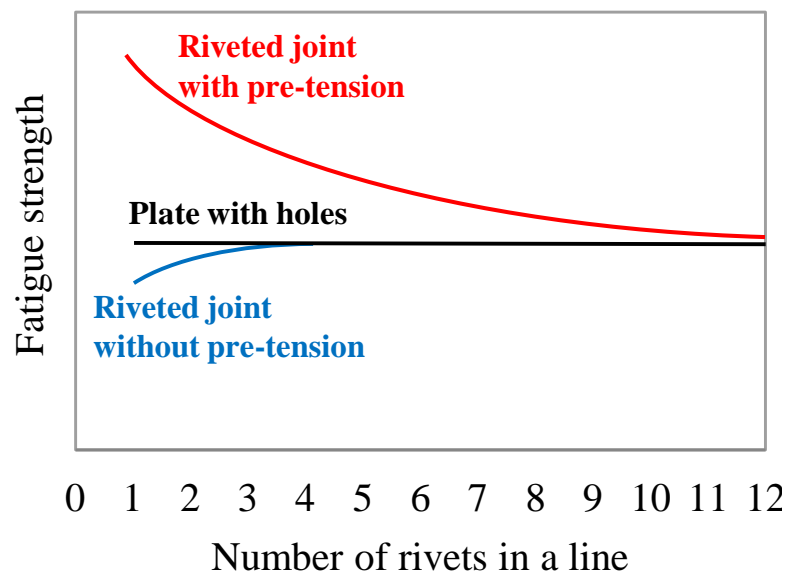

Fig. 3.7.B.2. Scheme of the fatigue strength of the joints with multiple rivets in a line (based on the test results in [37]).

Table 3.7.B.1. The Neuber constant for steels and wrought irons [36].

\begin{tabular}{|c|c|}
\hline Notch type & $\begin{array}{c}\sqrt{a}(\mathrm{~mm}), \\
\mathrm{S}_{\mathrm{ut}} \text { in MPa }\end{array}$ \\
\hline $\begin{array}{c}\text { Transverse } \\
\text { hole }\end{array}$ & $174 / \mathrm{S}_{\mathrm{ut}}$ \\
\hline Shoulder & $139 / \mathrm{S}_{\mathrm{ut}}$ \\
\hline Groove & $104 / \mathrm{S}_{\mathrm{ut}}$ \\
\hline
\end{tabular}

\section{Appendix C}

Based on Eq. (3.7.A.1), the surface modification factor was calculated with a hot-rolled finish assumption as $k_{a}=0.917$. Because the most fatigue prone detail is located at the rivet holes at the bottom flange of the I-beam and to make the analysis simpler, the outer plate of the lower flange is assumed to be subjected to only axial stress. Thus, the size factor for the axial loading is $\mathrm{k}_{\mathrm{b}}=1$, and the load factor for the axial loading is $\mathrm{k}_{\mathrm{c}}=0.85$. Note that it is also possible to obtain the size factor based on the real I-section geometry using the effective dimension method and setting the axial load factor to unity. A conservative average temperature of $T_{c}=0$ degrees Celsius at the location of bridge (Basel City, Switzerland) was chosen and results in a temperature factor of $\mathrm{k}_{\mathrm{d}}=0.988$. A reliability factor of $99 \%$ (i.e., $\mathrm{z}_{\mathrm{a}}=2.326$ ) is considered for the analysis, which results in $\mathrm{k}_{\mathrm{e}}=0.814$. Based on Eq. (3.7.5.b) the fatigue endurance limit is $\mathrm{S}_{\mathrm{e}}^{\prime}=176 \mathrm{MPa}$. The modified fatigue endurance limit is then obtained from Eq. (3.7.7) as $\mathrm{S}_{\mathrm{e}}=110.3 \mathrm{MPa}$. 


\section{Acknowledgments}

This research was funded by the Swiss Commission of Technology and Innovation (CTI) (grant No. 12993.1 PFIW-IW). Financial and technological support from the S\&P Clever Reinforcement AG Company and the Swiss Federal Railways (SBB) are also acknowledged. The author would also like to thank Mr. N. Popovic and Dr. G. Feltrin from Empa for their collaboration in the deployment of the monitoring system.

\section{References}

1. J. Bien, L. Elfgren, J. Olofsson, Sustainable Bridges, Assessment for Future Traffic Demands and Longer Lives, Dolnoslaskie Wydawnictwo Edukacyjne, Wroclaw 2007.

2. Report Card for American Infrastructure, American Society of Civil Engineering, transportation Bridges, 2009 Grade C.

3. IEAust (1999), Report Card on the Nation's Infrastructure, The Institution of Engineers, Australia, December.

4. Yamada, K., Ojio, T. and Inden, T. (2002), Bridge monitoring and weigh-in-motion systems in Japan, Post-IABSE Workshop on Structural Monitoring of Bridges, Monash University, Melbourne, Australia.

5. Ghafoori, E., Motavalli, M., Flexural and interfacial behavior of metallic beams strengthened by prestressed bonded plates. Composite Structures, 2013, 101 , pp. 22-34

6. Ghafoori, E., Interfacial stresses in beams strengthened with bonded prestressed plates, Engineering Structures, 2013, 46 , pp. 508-510.

7. Huawen Y, König C, Ummenhofer T, Shizhong Q, Plum R. Fatigue performance of tension steel plates strengthened with prestressed CFRP laminates. J Compos Constr 2010; (January 29).

8. Täljsten B, Hansen CS, Schmidt JW. Strengthening of old metallic structures in fatigue with prestressed and non-prestressed CFRP laminates. Constr Build Mater 2009;23(4):1665-77.

9. R. Wang and A. Nussbaumer, (2009). Modelling fatigue crack propagation of a cracked metallic member reinforced by composite patches, Engineering Fracture Mechanics, Elsevier Ltd., vol. 76, p. 1277-1287, doi:10.1016/j.engfracmech.2009.02.004

10. P. Colombi, A. Bassetti, and A. Nussbaumer (2003). Crack growth induced delamination on steel members reinforced by prestressed composite patch, Blackwell Publishing Ltd., Fatigue Fract Engng Mater Struct, vol. 26, no. 5, p. 429-437.

11. Wu, C., Zhao, X.L., Chiu, W.K., Al-Mahaidi, R. and Duan, W.H. (2013), Effect of fatigue loading on the bond behaviour between UHM CFRP plates and steel plates, Composites Part B: Engineering, 50(2013), 344-353.

12. Wu, C., Zhao, X.L. Al-Mahaidi, R. and Emdad, M.R. and Duan, W.H. (2013), Fatigue Tests on Steel Plates with Longitudinal Weld Attachment Strengthened by Ultra High Modulus CFRP Plate, Fatigue and Fracture of Engineering Materials and Structures36 (10), pp. 1027-1038. 
13. Ghafoori, E., Motavalli, M., Analytical calculation of stress intensity factor of cracked steel Ibeams with experimental analysis and 3D digital image correlation measurements, Engineering Fracture Mechanics, 2011, 78 (18) , pp. 3226-3242.

14. Ghafoori, E., Schumacher, A., Motavalli, M. Fatigue behavior of notched steel beams reinforced with bonded CFRP plates: Determination of prestressing level for crack arrest, Engineering Structures, 2012, 45 , pp. 270-283.

15. Ghafoori, E., Motavalli, M., Botsis, J., Herwig, A., Galli, M. Fatigue strengthening of damaged metallic beams using prestressed unbonded and bonded CFRP plates, 2012, International Journal of Fatigue 44 , pp. 303-315.

16. Ghafoori E., Motavalli M., Nussbaumer A., Herwig A., Prinz G.S., Fontana M., Determination of minimum CFRP pre-stress levels for fatigue crack prevention in retrofitted metallic beams, Engineering Structures, submitted, 2014.

17. SHIGLEY's “Mechanical engineering design” / Richard G. Budynas, J. Keith Nisbett. Singapore : McGraw-Hill, 2008.1055S.:Ill.

18. MARIN J., "Mechanical Behavior of Engineering Materials", Prentice-Hall, Englewood Cliffs, N.J., 1962, p. 224.

19. J.B. Johnson, The materials of construction (1st ed.)John Wiley and Sons, New York (1897) pp. 537-47.

20. J.B. Johnson, Correspondence on 'The Launhardt Formula, and Railroad Bridge Specifications' Trans. Am. Soc. Civil Eng., 41 (1899), pp. 187-188

21. Ghafoori E., Prinz G.S., E. Mayor, Nussbaumer A., Motavalli M., Herwig A., Fontana M., Finite Element Analysis for Fatigue Damage Reduction in Metallic Riveted Bridges Using Pre-Stressed CFRP Plates, Polymers 2014, 6(4), 1096-1118.

22. http://en.wikipedia.org/wiki/Münchenstein_rail_disaster

23. ABAQUS, HKS. 2006. ABAQUS Standard User's Manual, Version 6.4. Hibbitt, Karlsson, and Sorensen, Inc.

24. http://www.tml.jp/e/product/strain_gauge/option/fgmh-1.html

25. SIA 269/1 - Erhaltung von Tragwerken - Einwirkungen. Swiss Society of Engineers and Architects (SIA), 2011, Zurich, Switzerland.

26. Ghafoori E., Motavalli M., Innovative CFRP Pre-stressing System for Strengthening of Metallic Structures, Journal of Composites for Construction (ASCE), submitted, 2014.

27. S\&P Clever Reinforcement Company AG, Verfahren zum Vorspannen eines Stahlbauwerkes sowie damit vorgespanntes Stahbauwerk. Swiss Patent, Patent No. CH 706630 B1.

28. Feltrin G., Jalsan K.E. and Flouri K., Vibration monitoring of a footbridge with a wireless sensor network, Journal of Vibration and Control, 2013, 19(15), 2285-2300.

29. Flouri K., Saukh O., Sauter R., Jalsan K.E., Bischoff R., Meyer J., Feltrin G., A versatile software architecture for civil structure monitoring with wireless sensor networks," Smart Structures and Systems, 2012, 10(3), 209-228.

30. Eurocode_3 (1993). "Design of steel structures - Part 1-9: Fatigue." European Standard EN 1-9. 
31. C.J. Noll and Lipson, Allowable working stress, society for experimental stress analysis, vol 3, no. 2, 1946 p. 29.

32. Charles R. Mischke, Prediction of stochastic endurance strength, Trans. Of ASME, Journal of Vibration, Acoustics, Stress and Reliability in Design, vol. 109, no. 1, January 1987, Table3.

33. R. Kiguel, A relation between theoretical stress concentration factor and fatigue notch factor deduced from the concept of highly stressed volume, Prof. ASTM, vol. 61, 1961, pp. 73-748.

34. E.A. Brandes, Smithells Metal Reference Book, 6th ed., Butterworth, London, 1983, oo. 22-128 to $22-131$.

35. E.B. Haugen and P.H. Wirsching, Probabilistic Design, Machine Design, vol. 47, no. 12, 1975 , pp. $10-14$.

36. George Sines and H.L. Waisman, Metal fatigue, McGraw-Hill, New York. Copyright 1969 by The McGraw-Hill Companies, Inc.

37. Yin, W.S. - Fang, Q.H. - Wang, S.X. - Wang, X.H.: Fatigue strength of high- strength bolted joints. IABSE Colloquium, Lausanne 1982, pp 707-714. 